\title{
Shunt Overdrainage: Reappraisal of the Syndrome and Proposal for an Integrative Model
}

\author{
Bienvenido $\operatorname{Ros}^{1, *}$, Sara Iglesias ${ }^{1}$, Jorge Linares ${ }^{2}$, Laura Cerro ${ }^{2}$, Julia Casado ${ }^{2}$ and Miguel Angel Arráez ${ }^{2,3}$ \\ 1 Pediatric Neurosurgery Division, Department of Neurosurgery, Regional University Hospital, \\ Avda. Carlos Haya s/n, 29010 Malaga, Spain; sara.iglesias.sspa@juntadeandalucia.es \\ 2 Department of Neurosurgery, Regional University Hospital, Avda. Carlos Haya s/n, 29010 Malaga, Spain; \\ jorge.linares.sspa@juntadeandalucia.es (J.L.); laura.cerro.sspa@juntadeandalucia.es (L.C.); \\ julia.casado.sspa@juntadeandalucia.es (J.C.); marraezs@uma.es (M.A.A.) \\ 3 Department of Surgery, Malaga University, 29010 Malaga, Spain \\ * Correspondence: bienvenido.ros.sspa@juntadeandalucia.es
}

Citation: Ros, B.; Iglesias, S.; Linares, J.; Cerro, L.; Casado, J.; Arráez, M.A. Shunt Overdrainage: Reappraisal of the Syndrome and Proposal for an Integrative Model. J. Clin. Med. 2021, 10, 3620. https://doi.org/ $10.3390 / \mathrm{jcm} 10163620$

Academic Editors: Maria A. Poca and Juan Sahuquillo

Received: 11 July 2021

Accepted: 12 August 2021

Published: 17 August 2021

Publisher's Note: MDPI stays neutral with regard to jurisdictional claims in published maps and institutional affiliations.

Copyright: (c) 2021 by the authors. Licensee MDPI, Basel, Switzerland. This article is an open access article distributed under the terms and conditions of the Creative Commons Attribution (CC BY) license (https:// creativecommons.org/licenses/by/ $4.0 /)$.

\begin{abstract}
Although shunt overdrainage is a well-known complication in hydrocephalus management, the problem has been underestimated. Current literature suggests that the topic requires more examination. An insight into this condition is limited by a lack of universally agreed-upon diagnostic criteria, heterogeneity of published series, the multitude of different management options and misunderstanding of relationships among pathophysiological mechanisms involved. We carried out a review of the literature on clinical, radiological, intracranial pressure (ICP), pathophysiological and treatment concepts to finally propose an integrative model. Active prophylaxis and management are proposed according to this model based on determination of pathophysiological mechanisms and predisposing factors behind each individual case. As pathophysiology is progressively multifactorial, prevention of siphoning with gravitational valves or antisiphon devices is mandatory to avoid or minimize further complications. Shunt optimization or transferal and neuroendoscopy may be recommended when ventricular collapse and cerebrospinal fluid isolation appear. Cranial expansion may be useful in congenital or acquired craniocerebral disproportion and shunting the subarachnoid space in communicating venous hydrocephalus and idiopathic intracranial hypertension.
\end{abstract}

Keywords: antisiphon device; craniocerebral disproportion; gravitational valves; pathophysiology; shunt overdrainage; siphoning; slit ventricle syndrome

\section{Evolution of Concepts and Current Pitfalls in Shunt Overdrainage Syndrome}

Early historical cases of excessive drainage of brain fluid have been previously reported in the literature [1-7]. In the contemporary era of neurosurgery, Fox and coworkers were the first to report ICP monitoring findings in shunted patients. In 18 patients with normal pressure hydrocephalus (NPH), mean cerebrospinal fluid (CSF) pressure values about $-220 \mathrm{~mm} \mathrm{H}_{2} \mathrm{O}$ for ventriculoperitoneal shunts (VPS) and about $-190 \mathrm{~mm} \mathrm{H}_{2} \mathrm{O}$ for ventriculoarterial shunts (VAS) were obtained in the upright position, these findings being explained by the siphoning action of shunts. Siphoning might be responsible for annoying postural headaches and cases of subdural hematoma and higher-pressure valves and/or VAS were recommended for patients expected to be upright for much of their waking period [8]. Portnoy contributed to this "mechanistic model" by developing an "antisiphon device" (ASD) to prevent siphoning [4,9]. ICP characteristics of postural siphoning were confirmed in 1990 by Chapman using a telemetric device in patients with VPS, VAS and ventriculopleural shunts. ASD were generally effective in restoring "normal pressures" in the upright position [10]. Pudenz also investigated the hypothesis of overdrainage caused by siphoning [11]. Siphoning was not always a negative effect of shunts: Bergsneider reported on the benefit of siphoning to induce ventricular hypotension in shunt non-responsive hydrocephalic patients [12]. 
Chronic overdrainage was also soon associated with recurrent shunt obstruction secondary to small ventricles, and subtemporal craniectomies were carried out in the 1970s to prevent this complication [13,14]. In 1982 Hyde-Rowan and coworkers first defined the so-called "slit ventricle syndrome" (SVS) as the clinical picture characterized by a triad: intermittent or chronic headaches, small ventricles on CT scan or ventriculogram, and slow refill of the palpable valve mechanism. These characteristic episodes, usually lasting from 10 to $90 \mathrm{~min}$, were considered to be secondary to ventricular catheter obstruction that was, therefore, episodic as well. The authors believed that subtemporal craniectomies were not successful in the long-term so prophylactic measures should be employed to prevent slit ventricles. Avoiding low-pressure valves, valve upgrading or in-line ASD implantation were recommended whenever a slit ventricle was encountered, even in asymptomatic patients [15]. Valve obstruction was only temporary in these episodes. Shunt patency was later documented in patients with headaches and small ventricles seen on isotope scan studies [16].

Overdrainage itself could lead to further symptomatology, which could be divided into acute and chronic manifestations [17]. Once chronic symptoms were established, algorithms including sequenced strategies (shunt revision, cranial expansion), then were necessary [18]. In the early 1990s, Abbot described three distinct categories in shunt overdrainage according to ICP monitoring: headaches from hypotension (ICP drop when sitting as a result of shunt siphoning), intermittent headache episodes (high-pressure waves were recorded) and a third group of patients that showed no relation of symptoms to pressure. ASD implantation was recommended in the first group, shunt revision or cranial expansion in the second and no treatment, shunt removal, headache clinic or medication for migraine in the third group [16]. In 1993, Rekate proposed a subclassification of SVS divided into five distinct syndromes by adding the so-called "shunt failure with small ventricles" and "intracranial hypertension with working shunt" types [19]. Baskin implemented an ICP-based algorithm for shunt removal in SVS refractory to increased shunt resistance and medical therapy: shunt withdrawal, endoscopic third ventriculostomy (ETV) or LPS shunts were employed according to ventricular dilatation and ICP measures [20]. Later on, Eide carried out calvarial expansion in patients with intracranial hypertension, considering SVS as the result of craniocerebral disproportion (CCD) with impaired intracranial compliance [21], whereas implantation of an ASD and/or higher-pressure valve was recommended in patients with abnormally reduced ICP [22].

Nowadays, different classifications and algorithms have been published concerning SVS $[23,24]$ but the most accepted concepts of shunt overdrainage are related to what has become known as "overdrainage syndromes" [25] or lately "shunt related headaches" [26]. A possible equivalence between these different classifications has been proposed [27]. Rekate considered shunt overdrainage to be an entity characterized by the appearance of severe headache, i.e., that which interferes with activities of daily living, in patients with a CSF shunt valve and normal or smaller than normal ventricles. The five known different categories have now been re-named: severe intracranial hypotension or low-pressure headaches (analogous to spinal headaches), intermittent obstruction of the ventricular catheter ("slit ventricle syndrome" itself), intracranial hypertension with small ventricles and a failed shunt, intracranial hypertension with a working shunt and headaches unrelated to shunt function ("shunt-related migraine") [26]. These concepts, which have been globally accepted, include the whole spectrum, so a variety of symptoms, clinical presentations, radiological findings and pressure readings can be expected [28].

Recent reports, however, have suggested that the evidence about overdrainage is not as robust as presumed and that the topic requires yet more examination [4]. An insight into the condition is limited by a lack of universally agreed-upon diagnostic criteria, heterogeneity in the clinical characteristics of patients included in studies and a multitude of non-evidence-based management options. Besides, patients can develop different causes of their headaches over time [29]. The clinical-radiological picture is more complex than the classic descriptions of headaches in patients with small ventricles. Symptoms can also 
appear in patients with normal or large ventricles [30] and slow valve refilling does not necessarily mean valve malfunction or overdrainage [31]. Both the "intracranial hypertension with a working shunt" and "shunt failure without ventricular enlargement" types are particularly difficult to distinguish in practice or even directly overlap. Similarities with the so-called "normal volume hydrocephalus" of Engel [32], "shunt malfunction without ventricular dilatation" of McNatt [33] and "hydrocephalic pseudotumor" of Rekate [19] have been proposed [27]. Additionally, the term "headache or non-shunt-related migraine" seems to be a catch-all definition [27]. Terms such as CCD, SVS and chronic overdrainage are unfortunately sometimes used as synonyms [34]. On the other hand, important problems also exist regarding the pathophysiology of shunt overdrainage. Indeed, this has been considered one of the issues which we do not know (but should) about hydrocephalus [35]. In the current literature, it has been widely accepted that siphoning of CSF leads to intracranial hypotension, which may progress to SVS, but a significant number of papers are observational clinical reports that do not offer a pathophysiological hypothesis. In clinical practice, more than one pathophysiological mechanism may be involved in a single case, perhaps with one predominating which should determine the main treatment strategy [27]. On the other hand, some attention needs to be shifted to the prophylaxis of overdrainage in susceptible patients [4]. Finally, surgical management of chronic overdrainage is becoming more complex, as surgeons have to deal with new adjustable gravitational valves or different models of ASD.

The lack of standardized clinical criteria for its diagnosis explains the different rates of shunt overdrainage (from $1 \%$ to over $50 \%$ of shunted subjects) reported $[27,36]$. In a recent survey sent to active ASPN members regarding shunted-hydrocephalus management, most respondents considered chronic CSF overdrainage to be a rare complication of shunting (no more than 15\%) in their practice, attributing chronic headaches to medical reasons (migraines, tension) with patients being frequently referred to stress management or pain clinics [37]. There may have been undiagnosed overdrainage behind a certain percentage of shunt malfunctions [38] as overdrainage predisposes to obstruction of the ventricular catheter [39]. According to Rekate, at least one-third of chronic shunted patients followed for more than 5 years will have serious chronic headaches, although the picture could be subclinical for decades [26]. Radiological overdrainage can appear in various percentages of shunted patients, ranging from less than $10 \%$ up to even $85 \%$ [27]. In our series of 166 shunted patients that we followed for a mean of 93 months, $56 \%$ developed some form of symptomatic overdrainage, which was the most usual reason for surgical revision due to valve malfunction. Antisiphon and/or gravitational devices were used to treat symptomatic overdrainage but we did not give active prophylaxis for overdrainage during that period of time [40]. However, it is not just a matter of a high rate but also of severity. Patients who developed severe overdrainage had unpredictable responses to a gradual increase in system resistance and required several surgical revisions of their shunts before they became symptom-free [40]. Furthermore, symptomatic overdrainage was associated with a worse cognitive outcome measured by the HOQ-Spanish version [41].

In an attempt to confront these limitations, we will now consider clinical, radiological, ICP, pathophysiological and treatment concepts separately, to finally propose an integrative model for the management of shunt overdrainage syndrome (SOS).

\section{Clinical Manifestations in Shunt Overdrainage}

Overdrainage of CSF may appear in an acute manner. Postoperative extradural hematoma [42] and the development of posterior reversible encephalopathy [43] have been described, caused by intraoperative overdrainage of CSF with rapid reduction in ICP as a result of a craniotomy or CSF diversion procedure. Regarding chronic overdrainage, we should always consider a silent period of asymptomatic (radiological) overdrainage of variable duration. Some patients do not even develop symptoms during low pressure stages [44]. When symptoms appear, they usually start as a "low-pressure headache", headache of postural characteristics or "spinal headache", with the patient unable to toler- 
ate sitting up. The symptom complex may also include nuchal or upper back pain, nauseavomiting, dizziness, fatigue, irritability, gait disturbance, diplopia, seizures, lethargy, etc. $[29,45]$. A sinking skin/bone flap may appear in shunted patients with decompressive craniotomies [46,47]. The "orthostatic intolerance syndrome", a rare dysautonomic condition related to fourth ventricle dilatation, may simulate a low ICP state [48-50]. Compressive myeloradiculopathy may occasionally occur due to ingurgitation of the venous epidural plexus together with meningeal thickening [51-53]. Similarities with spontaneous intracranial hypotension (SIH) have been described by some authors [54]. This entity has been recently termed overshunting-associated myelopathy (OSAM), and an association with jugular vein occlusion has been postulated $[55,56]$.

Low-pressure symptoms may evolve to intermittent headaches and the latter to chronic states with developmental delay, decline in school performance and social withdrawal. Multiple shunt revisions are frequently present in clinical records. The so-called "dorsal midbrain syndrome" (conjugate vertical gaze palsy, parkinsonism, memory loss, fluctuation in the level of consciousness, hypothalamic dysfunction, hypersalivation, peripheral facial palsy and blepharospasm) has also been reported as a result of overdrainage, upward midbrain herniation and aqueduct obstruction [57]. Finally, symptoms and signs of sustained intracranial hypertension may appear (papilledema, altered consciousness, bradycardia or systemic hypertension) $[29,34,58]$ with management of these states sometimes being a life-threatening emergency [59].

\section{Radiology in Shunt Overdrainage}

In the initial phase of ventricular emptying, extra-axial collections of fluid or blood may appear, hypodense, isodense or hyperdense on CT depending on the acute, subacute or chronic blood content $[42,60]$. Although most patients show small ventricles on imaging, moderate- or normal-sized ventricles are also found [61]. MRI studies may show widened brain sulci, parenchymal calcifications or overshunting-associated myelopathy findings in some cases $[51-53,55,56,62,63]$. The radiological compression may not have any clinical repercussions [56].

The final ventricular size and shape are the result of the initial size, the reconfiguration of the cerebral mantle and the presence of porencephaly. Ventricular collapse with no CSF around the ventricular catheter tip ("tip environment") is characteristic of SVS [64]. Sometimes, a transient increase in the size of the ventricles on imaging is observed during the period of symptom exacerbation, followed by a decrease during symptom remission [65]. The presence of compartments or sustained ventricular isolation may be a consequence of SVS [66].

Chronic shunting in infants can lead to premature sutural fusion (suture sclerosis) and cranial vault or skull base bone changes, such as microcephaly, dolichocephaly, laminated thickening of the calvarium or sinus hyperpneumatization $[67,68]$. CCD may be present in the supratentorial and infratentorial compartments (acquired Chiari) $[34,69,70]$. Spinal canal stenosis may also be present [71,72]. Figure 1 shows some examples with the main radiological characteristics of shunt overdrainage. 


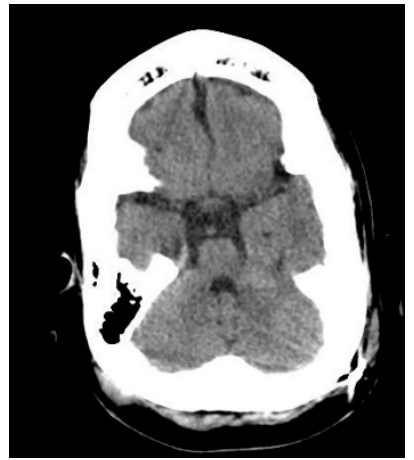

(A)

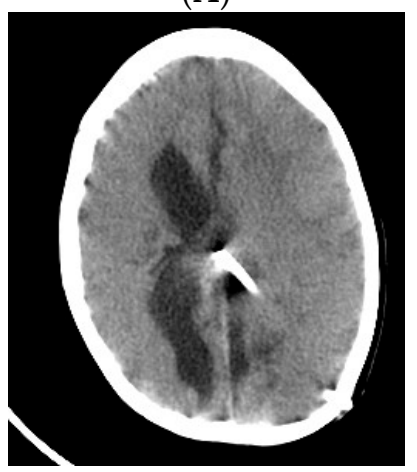

(E)

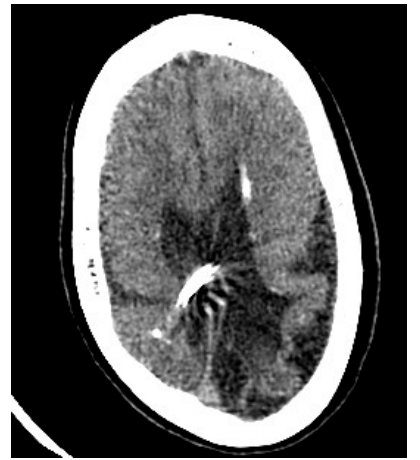

(B)

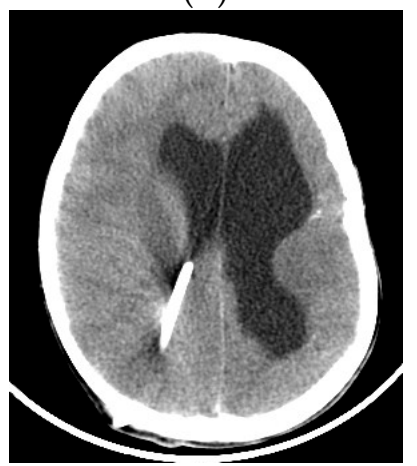

(F)

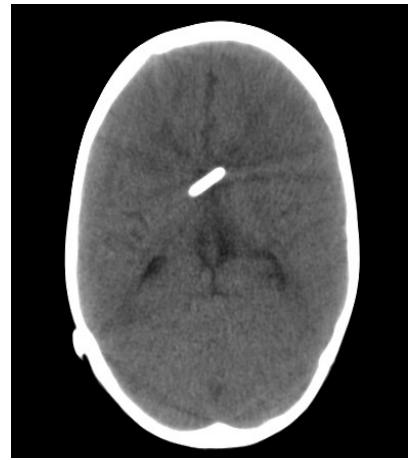

(C)

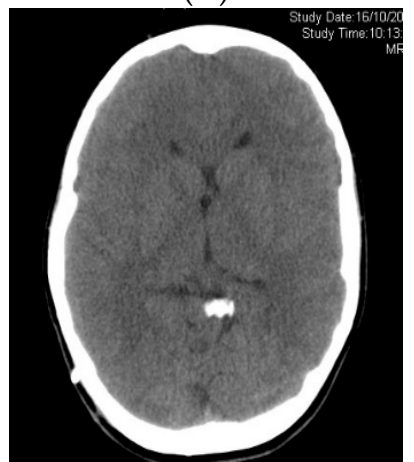

(G)

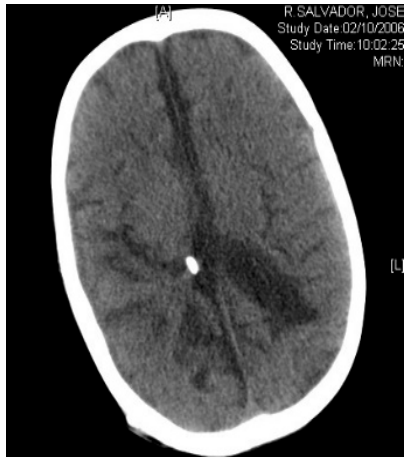

(D)

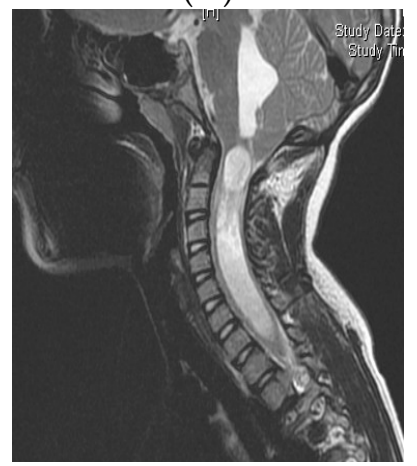

(H)

Figure 1. (A,B) A 5-year-old patient, shunted at birth after posthemorrhagic hydrocephalus. Postural symptoms. White matter damage with brain atrophy, small non-collapsed ventricles, extra-axial fluid collections, widened brain sulci, calcifications, laminated thickening of the calvarium, dolichocephaly and sinus hyperpneumatization. Shunt exchange with GV implantation was carried out, followed by clinical improvement. (C) An 8-year-old, shunted at birth after posthemorrhagic hydrocephalus. Complete ventricular collapse. Clinically, the patient presented sustained intracranial hypertension with papilledema, altered consciousness and bradycardia. Symptoms improved after shunt optimization by implanting an "in line" adjustable valve harboring a flow control device. (D-F) Ventricular collapse may be incomplete (D), unilateral (E) or focal (F). Non-collapsed areas may increase in size as a result of CSF isolation (E,F) and therefore can be considered for shunt transferring. (G) The catheter tip may be located outside the ventricular system (cisterns or extra-axial space). (H) Isolated fourth ventricle and syringomyelia as a result of sustained supratentorial overdrainage.

\section{ICP Patterns in Shunt Overdrainage}

The type of overdrainage cannot be determined based solely on clinical symptoms [73]. Therefore, ICP monitoring can be a useful tool [74]. Patients with low or high ICP may present with similar symptoms and radiological findings [75] and high ICP values might be present in patients with mild symptoms or even asymptomatic patients [74].

Early ICP monitoring reports showed that standard differential pressure VAS, VPS and ventriculopleural shunts all caused, in normal and chronically shunted patients, a rapid, "dramatic" linear fall in intraventricular pressure as the subjects were brought into the upright position. The fall started when the angle of body elevation was greater than 25 to $35^{\circ}$ and reached pressures in the range of -15 to $-35 \mathrm{~cm} \mathrm{H}_{2} \mathrm{O}$ [10] or -20 to $-25 \mathrm{~cm}$ according to other authors [19]. Recently, standardized positional testing may identify hypotensive overdrainage patterns. A low baseline ICP (slightly positive, i.e., around $5 \mathrm{mmHg}$ ) in a recumbent position is followed by an immediate ICP drop to slightly negative values (i.e., $-5 \mathrm{mmHg}$ ) in the first minute after sitting up and then by a gradual ICP decrease over the next $25 \mathrm{~min}$ to a minimum of less than $-10 \mathrm{mmHg}$ [45]. In these patients, overnight ICP monitoring studies show low or negative basal pressures $(\mathrm{Pb})$ in the horizontal position with a further decrease in pressure to a value lower than $-10 \mathrm{mmHg}$ in tilting tests. In infusion tests, Weerakkody reported $\mathrm{Pb}$ in the supine position $<0 \mathrm{mmHg}$, ICP at the plateau phase lower than critical pressure for specific 
shunt, Rcsf $<8 \mathrm{mmHg} / \mathrm{ml} / \mathrm{min}$, pulse amplitude baseline $<2 \mathrm{mmHg}$ and RAP index $<0.6$ [44]. According to Eide, the ICP pulse pressure amplitude should stay on average below $4 \mathrm{mmHg}$ in normal conditions and in shunt overdrainage, SIH and shunt nonresponders. Figures above $4 \mathrm{mmHg}$ are found in hydrocephalic patients prior to shunting or with shunt underdrainage. When ICP is less than $-15 \mathrm{mmHg}$, a slight increase in pulse pressure amplitude can be found in adult patients [76].

On the other hand, chronic shunted patients may develop patterns of intracranial hypertension. In early studies, mean ICP rise $>20$ and peaks $>50 \mathrm{mmHg}$ were encountered in patients with "intermittent" symptoms [19]. Recently, in overnight ICP monitoring (OIM) studies, ICP recordings showed irregular traces with a mean ICP $>20 \mathrm{mmHg}$, triangular shape of ICP pulse waveform and an increase in frequency and amplitude of vasogenic waves (B wave storms and recurrent plateau waves) [28,34,74]. An ICP trace can be divided into baseline intervals and wave intervals. A relative increase in the mean ICP (with ICP peaks $>25 \mathrm{mmHg}$ or even $>50 \mathrm{mmHg}$ ), RAP index (RAP peaks $>0.6$ ) and in the spectral parameters AMP and SLOW ( $>5 \mathrm{mmHg}$ ) have been described during the wave episodes compared to baseline $[19,28,29,45]$. In infusion tests, $\mathrm{Pb}$ is usually high but the pulse wave rarely visible; when collapsed ventricles open, pressure stabilizes at a lower level with a pulse wave clearly visible [29,44].

Two main ICP patterns have been recently proposed by Czosnyka. Overdrainage related to ICP slow vasogenic waves has been proposed as opposed to postural overdrainage related to siphoning [77]. Figures 2 and 3 illustrate differences between hypotensive and hypertensive patterns is shunt overdrainage.

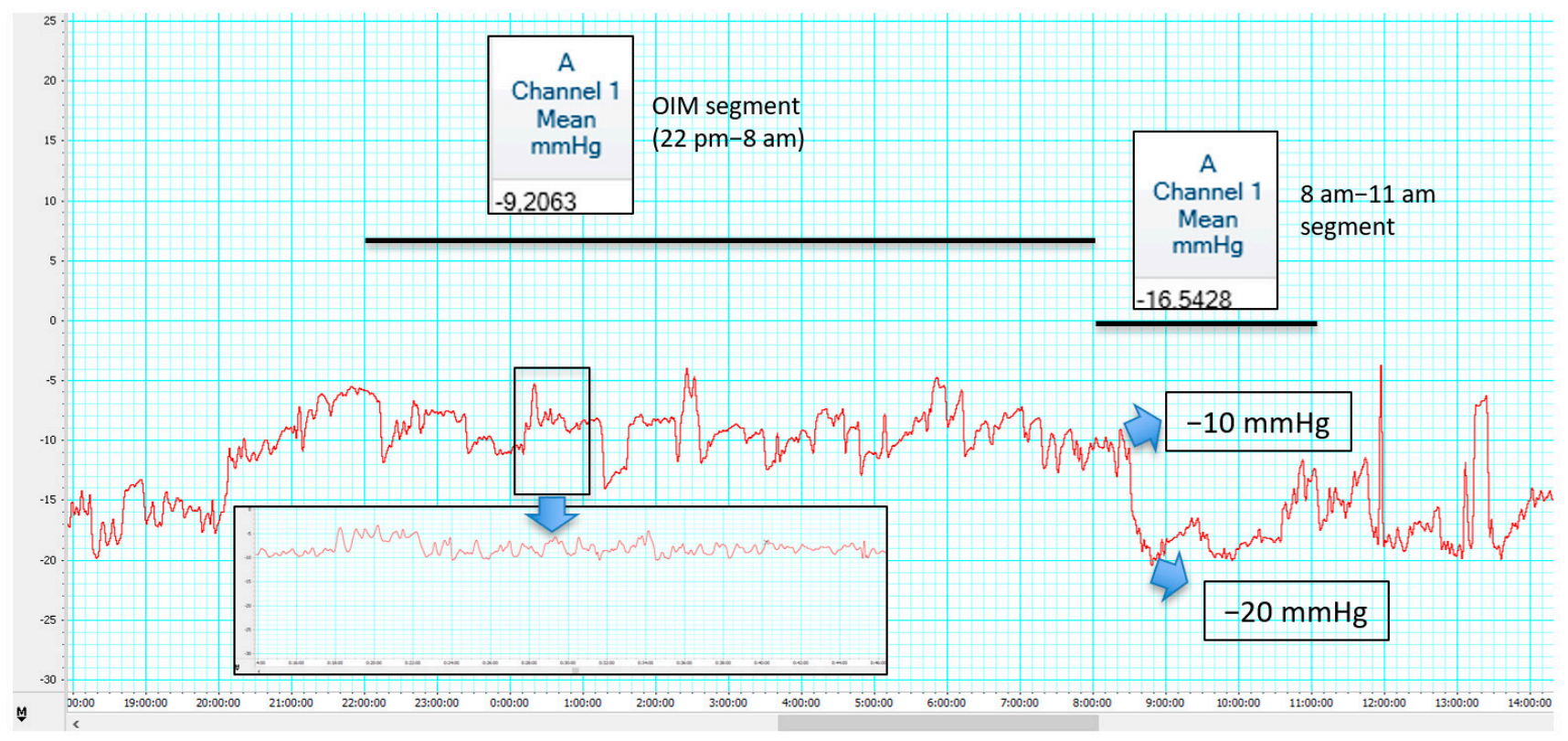

Figure 2. A 42-year-old female, pseudotumor cerebri treated by lumboperitoneal shunting (adjustable non-syphon control device). Chronic non-postural headache. Fundoscopy not fully reliable due to previous sequelae of papilledema. ICP monitoring revealed negative pressures during overnight ICP monitoring (OIM) segment (2200 to 0800) with a mean pressure of $-9 \mathrm{mmHg}$, presenting a fall from -10 to $-20 \mathrm{mmHg}$ at the time of the tilting test after awakening, followed by a discrete rise with a mean of $-16 \mathrm{mmHg}$ in the interval from 0800 to 1100 . Slow wave segments were also found (e.g., $\mathrm{B}$ waves up to $5 \mathrm{mmHg}$ in amplitude from 2400 to 0100). Intracranial hypotension was diagnosed and valve upgrading obtained symptomatic improvement. Codman Microsensor ${ }^{\circledR}$ ICP Transducer, Codman ${ }^{\circledR}$ ICP EXPRESS Monitor ${ }^{\circledR}$ (Integra LifeSciences Corporation, Princeton, NJ, USA)/ML856 PowerLab 26T, ML132 Bio Amp ADInstruments, INC/Personal Computer Chart v.8 software (ADInstruments, Dunedin, New Zealand). 


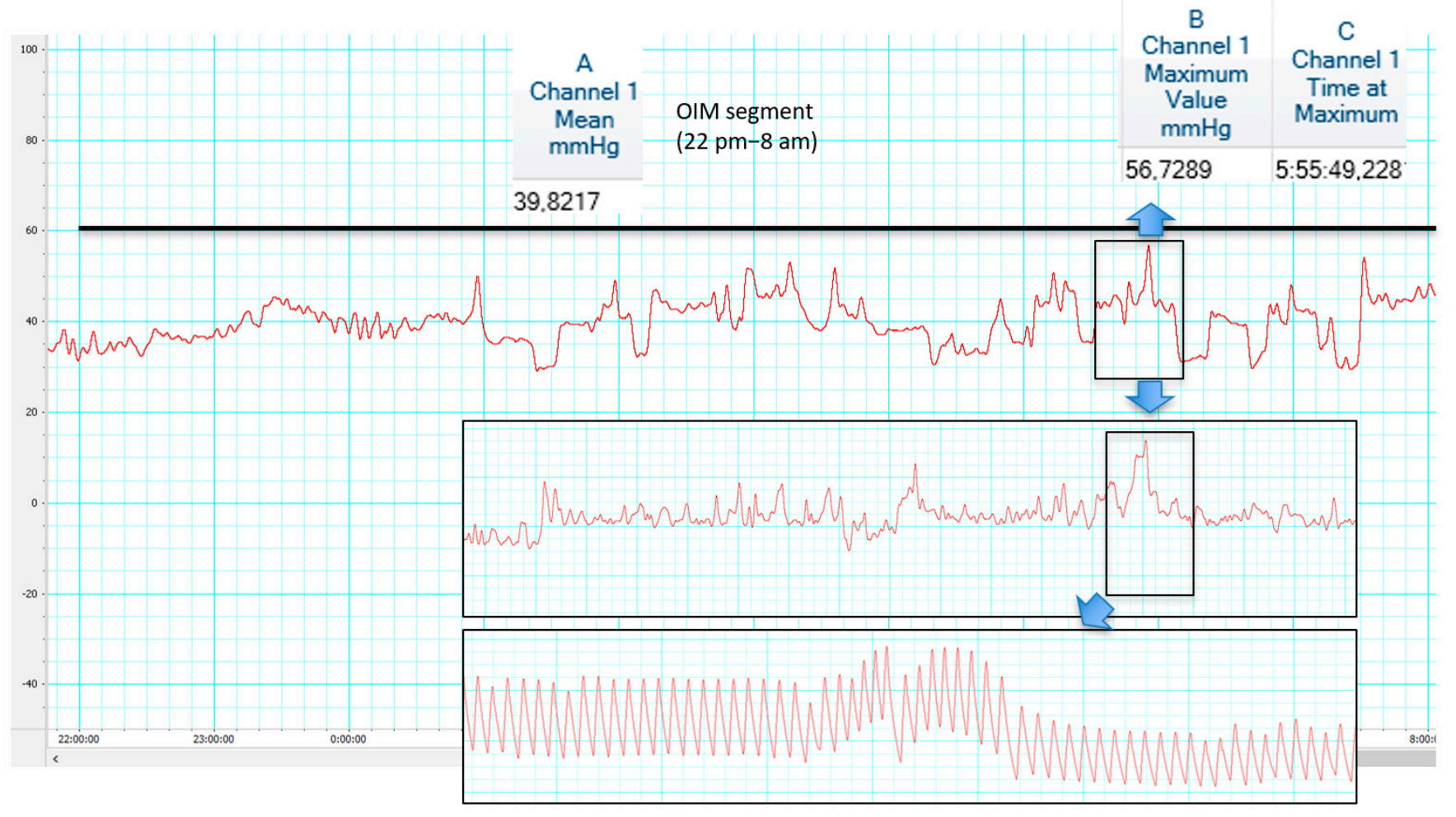

Figure 3. An 8-year-old patient with syndromic craniosynostosis and hydrocephalus, shunted at birth (also see Figure 5). Symptoms only partially improved after shunt optimization. ICP monitoring revealed irregular traces and raised ICP during OIM segment (2200 to 0800) with mean ICP of $39 \mathrm{mmHg}$ and ICP peak over $56 \mathrm{mmHg}$ at 05:55. High amplitude B waves (up to $20 \mathrm{mmHg}$ ) were found in slow wave segments where ICP pulse amplitude reached $20 \mathrm{mmHg}$ and waveform had a triangular shape. Re-do posterior cranial vault gradual distraction was performed. Codman Microsensor ${ }^{\circledR}$ ICP Transducer, Codman $^{\circledR}$ ICP EXPRESS Monitor ${ }^{\circledR}$ (Integra LifeSciences Corporation, Princeton, NJ, USA)/ML856 PowerLab 26T, ML132 Bio Amp ADInstruments, INC/Personal Computer Chart v.8 software (ADInstruments, Dunedin, New Zealand).

\section{Pathophysiological Theories in Shunt Overdrainage}

Different pathophysiological theories have been developed to describe the characteristic behavior of every single type of chronic shunt overdrainage. The condition, however, is clearly progressive and, therefore, the combination of mechanisms in a specific order and proportion occurs. The following suggested theories are analyzed individually to better understand their integration into a global theory (Figure 4).

\subsection{Siphoning}

The role of postural change is explained by the law of Stevin: $\mathrm{PP}=(\mathrm{ICP}-\mathrm{IAP})+\mathrm{HP}$, where PP is the perfusion pressure, ICP the intracranial pressure, IAP the intra-abdominal pressure and HP the hydrostatic pressure. When the patient goes from decubitus to an upright position a gradient appears due to gravity between the ventricles and the peritoneal cavity that is equivalent to the weight of the column of CSF inside the system (hydrostatic pressure). This "negative hydrostatic suction force" depends on the distance between both cavities and can easily exceed the opening pressure, resulting in siphoning, ventricular emptying (leading to "collapse") with intracranial hypotension, reduction in cerebral volume and expansion of the subarachnoid spaces or development of subdural CSF or blood effusions [36]. These complications are rare in infants because of the more elastic properties of the brain which limit the effects of brain shrinkage but conditions with white matter damage (post-hemorrhagic hydrocephalus-PHH-, aqueductal stenosis-AS-) are related with higher rates. In adults, previous subdural hematoma (SDH) or hygroma (SDHy), posttraumatic hydrocephalus (PTH) or chronic conditions with large ventricles and low brain 
elastance (LOVA, NPH or brain atrophy), favor siphoning-related complications [36,78-80]. Siphoning may also trigger other pathophysiological mechanisms.

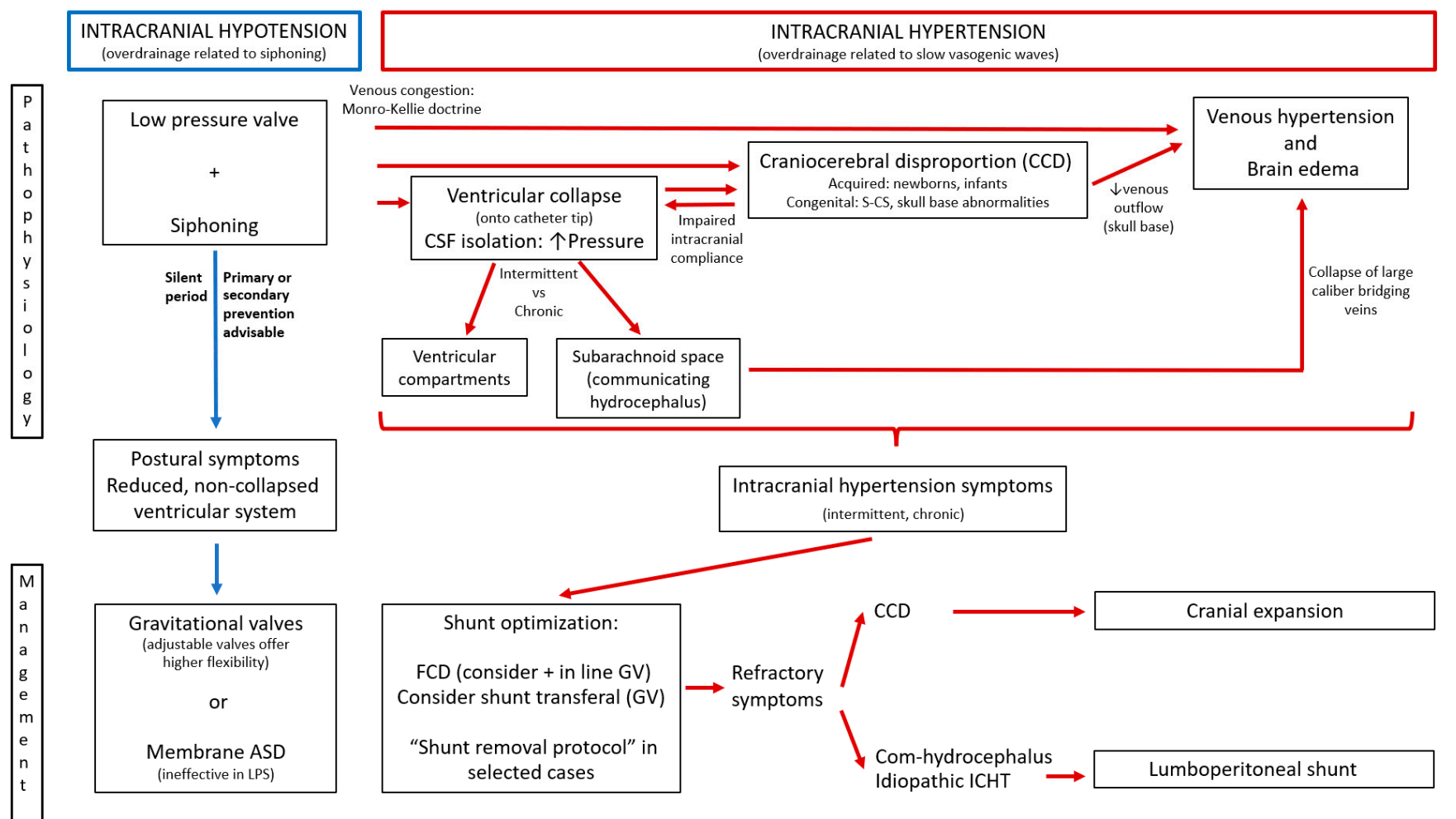

Figure 4. Shunt overdrainage syndrome. Integration of pathophysiological theories and algorithm for management. ASD: antisiphon device; FCD: flow control device; GV: gravitational valve; ICHT: intracranial hypertension.

\subsection{Ventricular Collapse and CSF Isolation}

When overdrainage leads to ventricular collapse onto the catheter tip, an intermittent or prolonged blocking of the shunt occurs and therefore CSF becomes isolated (stuck) from the main stream of circulation (the shunt). Distortion of the cerebral structures that follows CSF drainage may result in post-shunt ventricular asymmetry leading to unilateral collapse (with contralateral isolated ventricle) as a consequence of closure of the Monro by septum displacement in frontal catheters or medial displacement of the thalamus in atrial catheters $[66,81,82]$. In other cases, the pressure gradient between the supratentorial and infratentorial ventricular cavities leads to upward displacement of the midline cerebellar structures into the tentorial incisura, with subsequent distortion of the aqueduct. Trapping of the fourth ventricle may occur in the presence of membranes blocking fourth ventricle outlets due to post-infective or posthemorrhagic inflammatory processes or chemical or radiation-induced ventriculitis [36]. In communicating hydrocephalus, when the whole ventricular system is collapsed, CSF may become isolated in the subarachnoid space (with raised ICP in this compartment) and a "shunt pseudotumor" develops [25,83].

Predisposing factors for ventricular collapse and CSF isolation include shunt implantation during the first months of life $[36,68,83], \mathrm{PHH}$ of the newborn or premature $[38,60,83]$ or neonatal meningitis $[60,83]$, valves functioning well for several years $[68,84]$ and lowpressure opening valves $[36,84,85]$. On the other hand, this phenomenon is unlikely to occur in patients with severe brain atrophy (i.e., cerebral palsy) [36] and in patients with myelomeningocele [38].

\subsection{Acquired Craniocerebral Disproportion}

In newborn and infant patients, CSF shunting leads to early suture ossification with skull remodeling by formation of laminated layers of bone on the inner surface $[36,67]$. 
Approximation or overlapping of previously diastatic sutures and sinking of the fontanelle are predisposing factors $[36,86]$. A true secondary craniosynostosis with CCD occurs, with microcephaly and posterior fossa hypoplasia. As a result, impaired intracranial compliance with intracranial hypertension and cerebellar tonsillar herniation (acquired Chiari) may appear $[21,68]$. The latter may be facilitated by repeated lumbar punctures, external lumbar drainages or LPS that create a pressure gradient across the foramen magnum (Payner's "pressure gradient hypothesis") [69,87-89].

Shunt overdrainage will remain asymptomatic (silent period) while changes in ventricular size and CCD progress. Symptoms more often appear before the age of 10 years [83], with a peak between 6 to 9 years $[60,90,91]$. CCD is particularly frequent and severe in shunted patients with syndromic craniosynostosis or cranial bone abnormalities (osteopetrosis, achondroplasia, congenital hypoplasia of the posterior fossa) [70,92]. On the other hand, patients shunted after cerebral growth is complete are at a lower risk [89].

\subsection{Venous Congestion Theories}

According to the Monro-Kellie doctrine, a decrease in CSF volume and the induced negative ICP causes an increase in blood volume. This effect occurs mainly in the venous system, with a subsequent diffuse meningeal venous hyperemia and engorgement of the venous sinuses, which may be revealed on cranial and spinal MR images [51]. Increased elastance or stiffness appears, as this depends closely on the functioning of cerebral venous outflow mechanisms [26,93], making patients highly susceptible to even small changes in ICP [84]. Venous congestion may increase at the moment of shunt failure due to the increased ICP and a rapid collapse of large caliber bridging veins draining to the major venous sinuses [81]. This phenomenon is earlier and more severe in hydrocephalus of venous origin, congenital heart disease (increased pressure in the right cardiac chambers), pseudotumor cerebri, skull base abnormalities (achondroplasia, osteopetrosis, congenital hypoplasia of the posterior fossa, Chiari II) and syndromic craniosynostosis [26,94,95].

Recently, the "pulsatile vector theory" has been proposed and applied to the understanding of shunt overdrainage pathophysiology. Direct transmission of the CSF flow to the extrathecal compartment through the shunt produces a complete extinction of the centrifugal reflection wave at the aqueduct. The unchanged interstitial fluid shockwave leads to a ventricular collapse by progressive centripetal forces. In the subarachnoid space, the diastolic CSF pulse or "recurrent" wave (driving force of venous outflow at the cortical surface) may be reduced or eliminated and enlargement of venous vessels by increased volume load develops. Overdrainage symptoms appear whenever baseline ICP exceeds the venous pressure within the larger bridging veins, with increased outflow resistance causing venous congestion and cerebral edema. ICP may be further lowered by a resynchronization of physiological notch-filter and venous Starling-resistor, but the phenomenon would be irreversible with effect from a certain point [96].

Other capillary or venous mechanisms have been proposed. Jang described the socalled "capillary absorption laziness" theory. As CSF is not adequately absorbed in low or negative ICP conditions, in a situation of acute valve malfunction, the increased fluid pressures cannot be quickly compensated by a "lazy" or previously atrophied capillary system [30]. In the event of shunt malfunction, a rapid increase in ICP would lead to vein collapse and the interstitial fluid would not have enough time to dissipate through the venous system. Cerebral elastance increases and, as a result, ventricles fail to dilate and remain slit-like even in the face of a high ICP. On the other hand, according to Barami's "cerebral venous overdrainage" theory, during CSF diversion the Starling resistor effect on draining cortical veins may be rendered nonfunctional, leading to overdrainage of cerebral venous blood during upright positioning through cranial venous outflow tracts. This might explain the venous engorgement in the cervical epidural veins causing radicular and myelopathic symptoms in patients with CSF loss. Cerebral venous overdrainage (CVO) could be the pathophysiological mechanism behind low pressure hydrocephalus, SVS and pseudotumor cerebri [97]. 


\section{Management Strategies in Shunt Overdrainage}

When the reduction in ventricular size occurs early (during the first months of life), the rate of symptomatic overdrainage is multiplied. This could indicate the need for primary (at the time of first implantation) or secondary (at the time of shunt revision) preventive action [98]. The strategy of valve exchange to prevent chronic overdrainage is well tolerated and seems to improve the clinical outcome in terms of ventricular width, symptom relief and revision rate. In some centers, protocols for shunted patients include the mandatory rule to counteract the hydrostatic pressure [99]. In hydrocephalic children, preventive strategies with adjustable differential pressure valves and integrated gravitational units have a good rate of shunt survival [100].

Current valve technology offers a great variety of options to reduce CFS flow across the valve: high-pressure valves, membrane ASD, flow-controlled devices (FCD), adjustable differential pressure valves, adjustable differential pressure valves combined with fixed gravitational units, adjustable gravitational valves $(\mathrm{GV})$ or distal catheters having a smaller internal diameter [79,85,101-104].

All three main types of current ASDs (membrane ASD, FCD and GV) reduce the effect of siphoning but through a distinct mechanism. Not every device type is suitable for every patient [105]. In the case of membrane ASD, during verticalization, a switching diaphragm is progressively closed by the weight of the hanging hydrostatic column in the distal catheter. Additionally, the system works during inspiration in patients with a ventriculopleural shunt (inspiration may cause pressure gradients even when patients are lying down) $[79,106]$. These devices are ineffective with LPS [77]. Nevertheless, membrane ASD may stop drainage in the upright posture, leading to excessive accumulation. Besides, the membrane is highly susceptible to any kind of increased external tissue pressure, which can lead to functional obstructions [105]. Flow-controlled valves avoid increased drainage by closing their primary flow path when drainage exceeds a certain threshold. The second pathway is a longer and smaller diameter, resulting in increased flow resistance. This becomes relevant under high CSF differential pressure conditions [107,108]. However, these systems may limit rapid regulation in circumstances of high ICP [105]. On the other hand, no initial closing of the low resistance path is possible in an upright posture when the driving pressure gradient is not large enough (short patients who have a smaller hydrostatic pressure column) and re-opening has also been reported for slightly increased intraperitoneal pressure (obese patients with increased intraperitoneal pressure) [105]. FCD do not offer adjustability. Czosnyka found FCD to be helpful in overdrainage related to slow vasogenic ICP waves, as membrane ASD and GV might not be effective in such cases [77]. GV use small metallic balls as controlling weights instead of the hydrostatic column $[102,108]$. The Frankfurt horizontal plane should be used as a reference for implantation [109]. GV prevent uncontrolled drainage of the CSF during daytime activities, securing a minimum of recurrent CSF pulse wave to the subarachnoid space by a threshold amount of intraventricular CSF $[96,110,111]$. Independent opening pressures in horizontal and vertical orientation are allowed, but GV do not provide constant drainage in an upright posture. Differences in sitting and standing postures have been reported and precise adjustment to the height and intraperitoneal pressure is required. Consequently, adaptation to the individual patient is critical. In fact, non-programmable GV may not be advisable when the required opening pressure is difficult to estimate before surgery [105]. It should be taken into account that some patients with lower intracranial pressures may benefit from non-siphon control valves [112]. GV may cause under-drainage in bedridden patients [113].

In symptomatic patients, postural measures will help in transitory forms of intracranial hypotension (lumbar puncture, external lumbar or ventricular drainage or immediate postoperative CSF shunt) and in first episodes of presentation of postural headaches [84]. In refractory cases, cyproheptadine or topiramate have been employed but implantation of an in-line ASD could relieve symptoms both in children and adults in $85 \%$ of cases [114]. ASD and GV units may overcome the siphoning effect, but adjustability of GV has the 
advantage of higher treatment flexibility [115]. Some attempts have been made to determine the so called "vertical effective opening pressure" of the entire shunt system to determine the best adjustments for alleviating symptoms regarding the implantation of GV [116]. ICP measurements may be helpful in identifying the appropriate individual valve setting $[115,117]$. Changes in patient weight, height, mobility and activity should also be considered [118]. Adjustable GV may allow maintaining low pressure settings in decubitus in NPH patients, with significantly better outcomes and lower risk of subdural hematomas. In contrast, with differential pressure valves the pressure settings of the valve have to be rather high to prevent overdrainage, thereby potentially provoking underdrainage in a horizontal position [119]. Continuous clinical improvement may be obtained by decreasing opening pressure (if necessary, down to $0 \mathrm{mmH}_{2} \mathrm{O}$ ) and secondary responses can be obtained in initially non-responder patients $[120,121]$. NPH may even evolve to a "ultra-low-pressure" hydrocephalic state and downgrading valves and gravitational units may facilitate a "therapeutic siphoning" effect [122-124]. Barami's theory of uncontrolled cerebral venous overdrainage might explain why patients remain symptomatic even despite the addition of an ASD [97].

Once the ventricular system has collapsed, correction of the siphon effect may not be enough to control symptoms of overdrainage. Repositioning of the shunt can be carried out from the collapsed ventricle to another dilated or isolated area of the ventricular system, even to a porencephalic cavity. Neuronavigation or neuroendoscopic assistance is recommended as septostomies or transeptal multiperforated catheters are sometimes necessary $[82,84,125,126]$. The repositioned shunt system should be optimized according to the characteristics of the new proximal catheter location: in porencephalic areas high resistance systems may not be necessary as collapse onto the catheter tip is unlikely to occur. Neuroendoscopic or microsurgical fenestration may be necessary to treat a trapped fourth ventricle [127-129].

When the ventricular system is totally collapsed, shunt transferal is both difficult and risky. A protocol of controlled dilatation (the so-called shunt removal protocol) may be necessary by externalization of the shunt with continuous ICP recording. In some cases, these schemes allow a shunt independence state to be achieved when ventricular dilatation is tolerated with no increase in the ICP. In cases with symptomatic ventricular dilatation or raised ICP, ETV may be considered [20,26,130], although a favorable etiology and anatomical MRI findings should be considered for patient selection. Some authors consider that patients with myelomeningocele should be excluded [26]. Secondary ETV at the time of shunt malfunction may well be successful whereas planned removal of the shunt in overdrainage is an invasive procedure with more likelihood of failure [131]. In cases of increased ICP without ventricular dilatation, the condition behaves as a pseudotumor cerebri ("shunt pseudotumor") with CSF isolation in the subarachnoid space, and LPS implantation has been suggested. This procedure may be adequate for chronic overdrainage management in hydrocephalus of venous origin [26]. Drainage of the subarachnoid space permits a certain degree of ventricular dilatation by creating a favorable pressure gradient through the cortical mantle [23]. As the proximal catheter is located in the thecal sac, there is no possibility of collapse of this reservoir [132]. High-resistance valves or FCD should be considered to prevent overdrainage (including acquired Chiari development) [89,132-134]. Adjustable non-siphon-controlled valves have been successfully employed in LPS for patients with a diagnosis of idiopathic intracranial hypertension [135]. Ideally, these systems should harbor distal catheters having a smaller internal diameter. When patients are not candidates for LPS, drainage of CSF from the cisterna magna has been proposed [136].

In patients with CCD, shunt optimization, transferal, communication of isolated cavities, shunt removal or LPS may not be able to control symptoms of overdrainage. Particularly, patients with skull base abnormalities and a compromised foramen magnum (stenosis of the jugular foramen, Chiari I, myelomeningocele with Chiari II, achondroplasia, osteopetrosis or syndromic craniosynostosis) may have venous congestion associated with CCD. Although a short course of steroids helps control the symptoms [83] and antimigraine 
drugs may reduce the venous congestion [137], medical treatment is only justified while definitive therapy is planned. In these cases, cranial expansion procedures should be considered. Nowadays, suturectomies or subtemporal decompression techniques $[13,14,138]$ have been abandoned and parietal and posterior cranial vault expansion [21,139-141] or internal cranial decompression techniques $[142,143]$ are preferred. In patients with SVS and CCD, cranial expansion produced long-lasting relief of symptoms and a significant reduction in the mean ICP and ICP spikes [21]. Acquired Chiari may also be addressed by supratentorial cranial expansion [70] with the advantage that it can be used independently of whether the patient harbors a LPS or VPS and it does not require valve manipulation. LPS should be converted to VPS before suboccipital decompression $[69,144,145]$. On the other hand, patients with sinking skin/bone flap symptoms improve after correction of the overdrainage and cranioplasty.

\section{Proposal for an Integrative Model in Shunt Overdrainage}

Despite the superb contributions made by many authors on the topic of shunt overdrainage in the last half century, severe forms of shunt overdrainage syndrome still exist and an active prevention policy is lacking in many centers. Universally agreed-upon diagnostic criteria and classifications are necessary, probably based on a better understanding of the pathophysiological mechanisms and relationships among them. In this work we have proposed an integrative model of pathophysiology with clinical manifestations, radiological findings and ICP patterns to help determine the best (sometimes stepped) management strategy. Differences between pediatric patients and adults are based on the different etiologies, the characteristic CCD that occurs in infants and the duration of the overdrainage period and its influence on the complexity and severity of stablished pathophysiological mechanisms. Figure 4 offers an algorithm for management based on pathophysiology and Figure 5 illustrates the idea. The model is summarized in Table 1. Shunt optimization by prevention or correction of siphoning with GV or ASD is mandatory as the first therapeutic measure to avoid or minimize CSF isolation, CCD and venous hypertension, making shunt overdrainage less severe and easier to manage. Shunt optimization or transferal and neuroendoscopy may be recommended when ventricular collapse and cerebrospinal fluid isolation appear. Cranial expansion may be useful in congenital or acquired craniocerebral disproportion and shunting the subarachnoid space in communicating venous hydrocephalus and idiopathic intracranial hypertension.

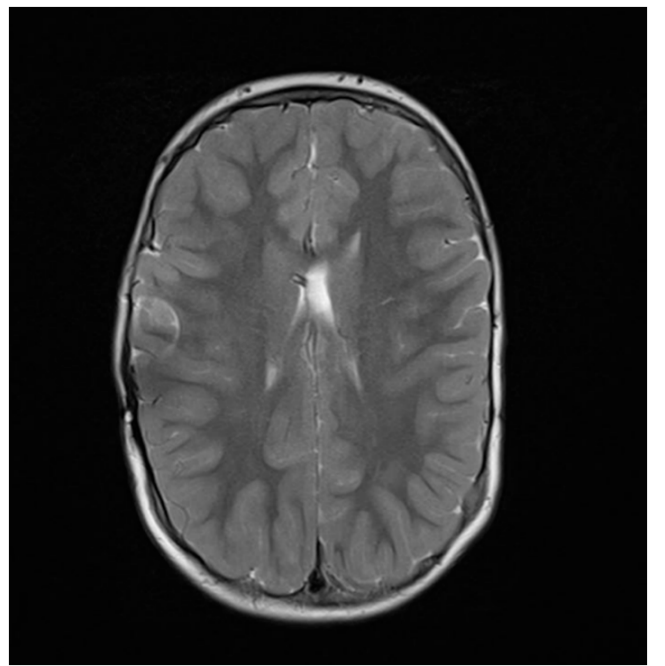

(A)

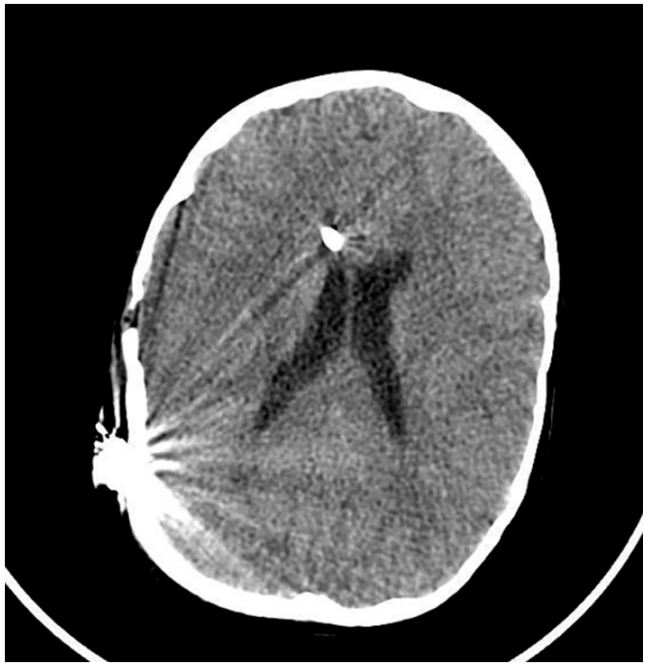

(B)

Figure 5. Cont. 


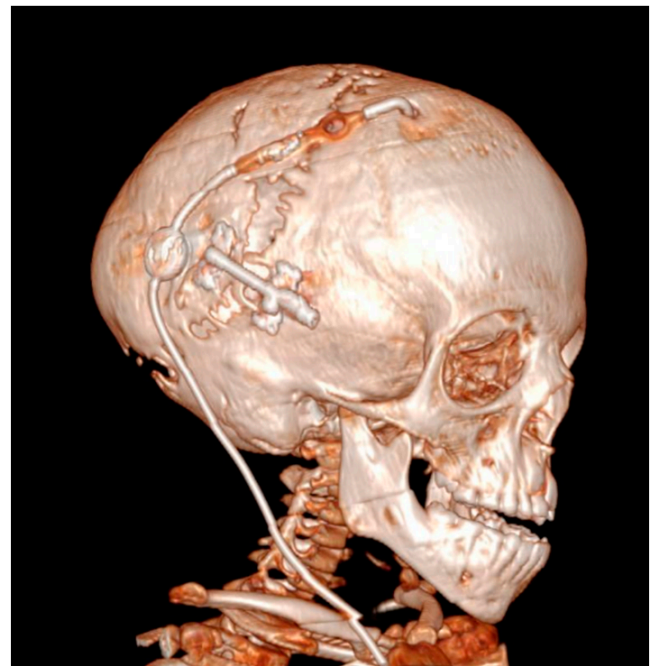

(C)

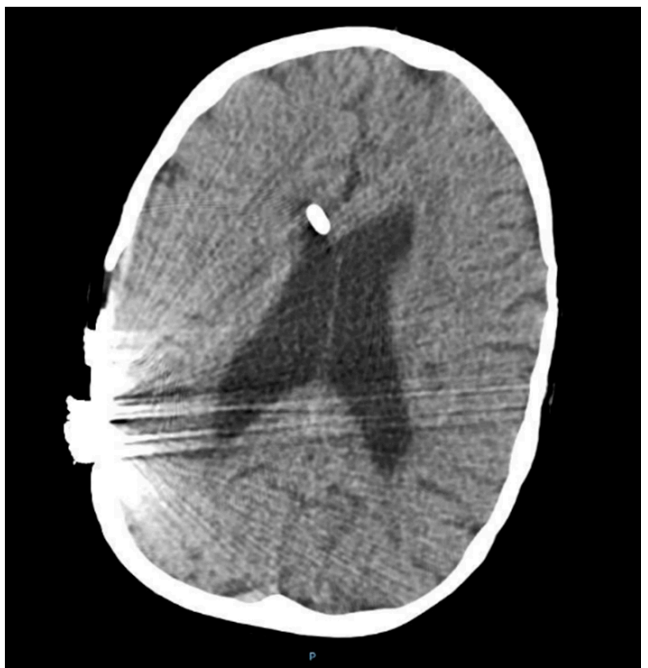

(D)

Figure 5. An 8-year-old patient with syndromic craniosynostosis and hydrocephalus, shunted at birth (also see Figure 3). Posterior cranial vault expansion by distraction osteogenesis performed before 1 year of age. The patient harbored an adjustable valve with FCD and in-line fixed antigravitational device. Episodes of headache and stiffness appeared, with slow valve refilling after pumping. (A) Ventricular collapse on MRI. (B) Improvement in ventricular size after shunt optimization (upgraded GV implanted in line) but symptoms only partially improved. (C) Re-do posterior cranial vault gradual distraction was performed with clinical and (D) significant radiological improvement. 
Table 1. Integrative Model for SOS.

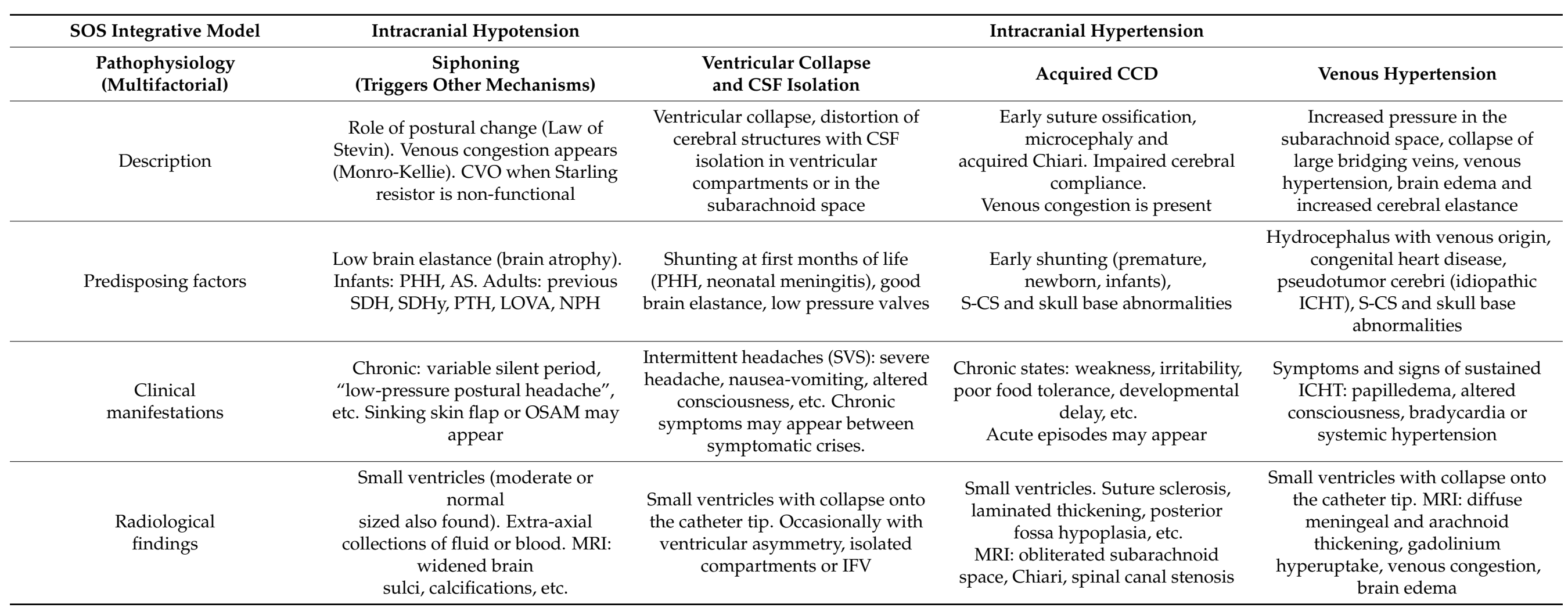


Table 1. Cont.

SOS Integrative Model

Pathophysiology (Multifactorial)

ICP patterns
Intracranial Hypotension

Siphoning (Triggers Other Mechanisms)

"Siphoning" pattern:

Low/negative $\mathrm{Pb}$

Decrease $<-10 \mathrm{mmHg}$

in tilting tests

Infusion tests: $\mathrm{Pb}<0, \operatorname{Rcsf}<8$,

pulse amplitude $<4, \mathrm{RAP}<0.6$

\section{Management}

strategies

Primary or

secondary

prevention

advisable

\section{GV}

Membrane ASD

(ineffective in LPS)

\section{Intracranial Hypertension}

Ventricular Collapse and CSF Isolation

\section{Venous Hypertension}

"Overdrainage related to ICP slow vasogenic waves":

Irregular traces, triangular shape of ICP pulse waveform, B waves storms Mean ICP > $20 \mathrm{mmHg}$, ICP peaks $>25 \mathrm{mmHg}$, RAP peaks $>0.6$

Raised AMP and SLOW during the wave episodes

Infusion tests: $\mathrm{Pb}$ usually high but pulse wave rarely visible

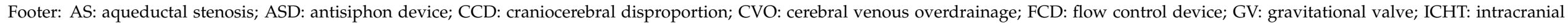

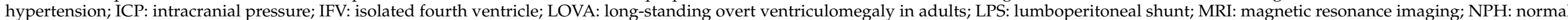

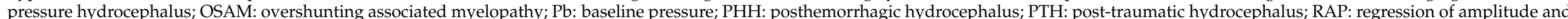

pressure index; Rcsf: CSF outflow resistance; S-CS: syndromic craniosynostosis; SDH; subdural hematoma; SDHy; subdural hygroma; SOS: shunt overdrainage syndrome; SVS: slit ventricle syndrome.

st. Shunt optimization: FCD recommended, consider combination with in-line GV.

(Consider shunt transferal or "shunt removal protocol" in selected cases)

2nd. Cranial expansion in congenital or acquired CCD, particularly in S-CS and skull base abnormalities 3rd. LPS in communicating hydrocephalus or idiopathic ICHT. High resistance systems recommended 
Author Contributions: Conception and design, B.R.; acquisition of data B.R., S.I., J.L., L.C. and J.C.; analysis and interpretation of data, B.R.; drafting the article, B.R. and S.I.; critically revising the article, M.A.A.; review submitted version of the manuscript, all authors; approved the definitive version of the manuscript on behalf of all authors, B.R. All authors have read and agreed to the published version of the manuscript.

Funding: This research received no external funding.

Data Availability Statement: No new data were created or analyzed in this study. Data sharing is not applicable to this article.

Conflicts of Interest: The authors declare no conflict of interest.

\section{References}

1. Grunert, P.; Charalampaki, P.; Ayyad, A. Concept and treatment of hydrocephalus in the Greco-Roman and early Arabic Medicine. Minim. Invasive Neurosurg. 2007, 50, 253-264. [CrossRef]

2. Rachel, R.A. Surgical treatment of hydrocephalus: A historical perspective. Pediatr. Neurosurg. 1999, 30, 296-304. [CrossRef]

3. Kompaje, E.J.; Delwel, E.J. The first description of a device for repeated external ventricular drainage in the treatment of congenital hydrocephalus, invented in 1744 by Claude-Nicolas Le Cat. Pediatr. Neurosurg. 2003, 39, 10-13. [CrossRef]

4. Cheok, S.; Chen, J.; Lazareff, J. The truth and coherence behind the concept of overdrainage of cerebrospinal fluid in hydrocephalic patients. Childs Nerv. Syst. 2014, 30, 599-606. [CrossRef]

5. Strenger, L. Complications of ventriculovenous shunts. J. Neurosurg. 1963, 20, 219-224. [CrossRef]

6. Hayward, R. "Casey and Theo": The children who changed the face of "Water-on-the-brain". Br. J. Neurosurg. 2009, 23, 347-350. [CrossRef]

7. Becker, D.P.; Nulsen, F.E. Control of hydrocephalus by valveregulated venous shunt: Avoidance of complications in prolonged shunt maintenance. J. Neurosurg. 1968, 28, 215-226. [CrossRef]

8. Fox, J.L.; McCullough, D.C.; Green, R.C. Effect of cerebrospinal fluid shunts on intracranial pressure and on cerebrospinal fluid dynamics 2. A new technique of pressure measurements: Results and concepts 3. A concept of hydrocephalus. J. Neurol. Neurosurg. Psychiatry 1973, 36, 302-312. [CrossRef]

9. Portnoy, H.D.; Schulte, R.R.; Fox, J.L.; Croissant, P.D.; Tripp, L. Antisiphon and reversible occlusion valves for shunting in hydrocephalus and preventing post-shunt subdural hematomas. J. Neurosurg. 1973, 38, 729-738. [CrossRef]

10. Chapman, P.H.; Cosman, E.R.; Arnold, M.A. The relationship between ventricular fluid pressure and body position in normal subjects and subjects with shunts: A telemetric study. Neurosurgery 1990, 26, 181-189. [CrossRef]

11. Pudenz, R.H.; Foltz, E.L. Hydrocephalus: Overdrainage by ventricular shunts. A review and recommendations. Surg. Neurol. 1991, 35, 200-212. [CrossRef]

12. Bergsneider, M.; Peacock, W.J.; Mazziotta, J.C.; Becker, D.P. Beneficial effect of siphoning in treatment of adult hydrocephalus. Arch. Neurol. 1999, 56, 1224-1229. [CrossRef]

13. Epstein, F.J.; Fleischer, A.S.; Hochwald, G.M.; Ransohoff, J. Subtemporal craniectomy for recurrent shunt obstruction secondary to small ventricles. J. Neurosurg. 1974, 41, 29-31. [CrossRef]

14. Holness, R.O.; Hoffman, H.J.; Hendrick, E.B. Subtemporal decompression for the slit-ventricle syndrome after shunting in hydrocephalic children. Pediatr. Neurosurg. 1979, 5, 137-144. [CrossRef]

15. Hyde-Rowan, M.D.; Rekate, H.L.; Nulsen, F.E. Reexpansion of previously collapsed ventricles: The slit ventricle syndrome. J. Neurosurg. 1982, 56, 536-539. [CrossRef]

16. Abbot, R.; Epstein, F.J.; Wisoff, J.H. Chronic headache associated with a functioning shunt. Usefulness of pressure monitoring. Neurosurgery 1991, 28, 72-77. [CrossRef]

17. Serlo, W.; Heikkinen, E.; Saukkonen, A.L.; Wendt, L.V. Classification and management of the slit ventricle syndrome. Childs Nerv. Syst. 1985, 1, 194-199. [CrossRef] [PubMed]

18. Epstein, F.; Lapras, C.; Wisoff, J.H. Slit-ventricle syndrome: Etiology and treatment. Pediatr. Neurosci. 1988, 14, 5-10. [CrossRef] [PubMed]

19. Rekate, H.L. Classification of slit-ventricle syndromes using intracranial pressure monitoring. Pediatr. Neurosurg. 1993, 19, 15-20. [CrossRef] [PubMed]

20. Baskin, J.J.; Manwaring, K.H.; Rekate, H.L. Ventricular shunt removal: The ultimate treatment of the slit ventricle syndrome. J. Neurosurg. 1998, 88, 478-484. [CrossRef]

21. Eide, P.K.; Helseth, E.; Due-Tønnessen, B.; Lundar, T. Changes in Intracranial Pressure after Calvarial Expansion Surgery in Children with Slit Ventricle Syndrome. Pediatr. Neurosurg. 2001, 35, 195-204. [CrossRef]

22. Eide, P.K. Quantitative analysis of continuous intracranial pressure recordings in symptomatic patients with extracranial shunts. J. Neurol. Neurosurg. Psychiatry 2003, 74, 231-237. [CrossRef]

23. Khorasani, L.; Sikorski, C.W.; Frim, D.M. Lumbar CSF shunting preferentially drains the cerebral subarachnoid over the ventricular spaces: Implications for the treatment of slit ventricle syndrome. Pediatr. Neurosurg. 2004, 40, 270-276. [CrossRef] 
24. Olson, S. The problematic slit ventricle syndrome. A review of the literature and proposed algorithm for treatment. Pediatr. Neurosurg. 2004, 40, 264-269. [CrossRef]

25. Rekate, H.L. Slit ventricle syndrome. Diagnosis and management. In Pediatric Hydrocephalus; Cinalli, G., Maxner, W.J., Sainte-Rose, C., Eds.; Springer: Berlin/Heidelberg, Germany, 2004; pp. 335-349.

26. Rekate, H.L. Shunt-related headaches: The slit ventricle syndromes. Childs Nerv. Syst. 2008, 24, 423-430. [CrossRef]

27. Ros, B.; Iglesias, S.; Martín, A.; Carrasco, A.; Ibáñez, G.; Arráez, M.A. Shunt overdrainage syndrome: Review of the literature. Neurosurg. Rev. 2018, 41, 969-981. [CrossRef] [PubMed]

28. Sainz, L.V.; Hockel, K.; Schuhmann, M.U. Chronic overdrainage syndrome: Pathophysiological insights based on ICP analysis: A case-based review. Childs Nerv. Syst. 2018, 34, 401-408. [CrossRef]

29. Hart, M.G.; Czosnyka, M.; Czosnyka, Z.H.; Fernandes, H.M. Combined Intracranial Pressure Monitoring and Cerebrospinal Fluid Infusion Study to Guide Management of Slit Ventricle Syndrome. Pediatr. Neurosurg. 2013, 49, 113-118. [CrossRef]

30. Jang, M.; Yoon, S.H. Hypothesis for intracranial hypertension in slit ventricle syndrome: New concept of capillary absorption laziness in the hydrocephalic patients with long-term shunts. Med. Hypotheses 2013, 81, 199-201. [CrossRef] [PubMed]

31. Piatt, J.H., Jr. Physical examination of patients with cerebrospinal fluid shunts: Is there useful information in pumping the shunt? Pediatrics 1992, 89, 470-473.

32. Engel, M.; Carmel, P.W.; Chutorian, A.M. Increased intraventricular pressure without ventriculomegaly in children with shunts: "normal volumen" hydrocephalus. Neurosurgery 1979, 5, 549-552. [CrossRef]

33. McNatt, S.A.; Kim, A.; Hohuan, D.; Krieger, M.; McComb, J.G. Pediatric shunt malfunction without ventricular dilatation. Pediatr. Neurosurg. 2008, 44, 128-132. [CrossRef] [PubMed]

34. Beez, T.; Munoz-Bendix, C.; Ahmadi, S.A.; Messing-Jünger, M.; Steiger, H.K.; Röhrig, A. Conservative and operative management of iatrogenic craniocerebral disproportion-a case-based review. Childs Nerv. Syst. 2019, 35, 19-27. [CrossRef] [PubMed]

35. Bergsneider, M.; Egnor, M.R.; Johnston, M.; Kranz, D.; Madsen, J.R.; McAllister, J.P., 2nd; Stewart, C.; Walker, M.L.; Williams, M.A. What we don't (but should) know about hydrocephalus. J. Neurosurg. 2006, 104 (Suppl. S3), 157-159. [CrossRef] [PubMed]

36. Di Rocco, C.; Massimi, L.; Tamburrini, G. Shunts vs endoscopic third ventriculostomy in infants: Are there different types and/or rates of complications? A review. Childs Nerv. Syst. 2006, 22, 1573-1589. [CrossRef]

37. Kraemer, M.R.; Sandoval-Garcia, C.; Bragg, T.; Iskandar, B.J. Shunt-dependent hydrocephalus: Management style among members of the American Society of Pediatric Neurosurgeons. J. Neurosurg. Pediatr. 2017, 20, 216-224. [CrossRef] [PubMed]

38. Breimer, G.E.; Sival, D.A.; Hoving, E.W. Low-pressure valves in hydrocephalic children: A retrospective analysis. Childs Nerv. Syst. 2012, 28, 469-473. [CrossRef]

39. Sainte-Rose, C.; Piatt, J.H.; Renier, D.; Pierre-Kahn, A.; Hirsch, J.F.; Hoffman, H.J.; Humphreys, R.P.; Hendrick, E.B. Mechanical complications in shunts. Pediatr. Neurosurg. 1992, 17, 2-9. [CrossRef] [PubMed]

40. Iglesias, S.; Ros, B.; Martín, A.; Carrasco, A.; Segura, M.; Delgado, A.; Rius, F.; Arráez, M.A. Surgical outcome of the shunt: 15-year experience in a single institution. Childs Nerv. Syst. 2016, 32, 2377-2385. [CrossRef]

41. Iglesias, S.; Ros, B.; Martín, A.; Carrasco, A.; Rius, F.; Arráez, M.A. Functional outcome in pediatric hydrocephalus: Results of applying the Spanish version of the Hydrocephalus Outcome Questionnaire. J. Neurosurg. Pediatr. 2018, 21, 224-235. [CrossRef]

42. Niimura, M.; Takai, K.; Taniguchi, M. Postoperative epidural haematomas associated with hydrocephalus caused by intraoperative overdrainage of cerebrospinal fluid: Two case reports with a literature review of 19 cases. BMJ Case Rep. 2015, 9, 1-5. [CrossRef] [PubMed]

43. Niwa, R.; Oya, S.; Nakamura, T.; Hana, T.; Matsui, T. Rapid intracranial pressure drop as a cause for posterior reversible encephalopathy syndrome: Two case reports. Surg. Neurol. Int. 2017, 8, 103. [CrossRef] [PubMed]

44. Weerakkody, R.A.; Czosnyka, M.; Schuhmann, M.U.; Schmidt, E.; Keong, N.; Santarius, T.; Pickard, J.D.; Czosnyka, Z. Clinical assessment of cerebrospinal fluid dynamics in hydrocephalus. Guide to interpretation based on observational study. Acta Neurol. Scand. 2011, 124, 85-98. [CrossRef] [PubMed]

45. Schuhmann, M.U.; Sood, S.; McAllister, J.P.; Jaeger, M.; Ham, S.D.; Czosnyka, Z.; Czosnyka, M. Value of Overnight Monitoring of Intracranial Pressure in Hydrocephalic Children. Pediatr. Neurosurg. 2008, 44, 269-279. [CrossRef] [PubMed]

46. Han, P.Y.; Kim, J.H.; Kang, H.I.; Kim, J.S. "Syndrome of the sinking skin-flap" secondary to the ventriculoperitoneal shunt after craniectomy. J. Korean Neurosurg. Soc. 2008, 43, 51-53. [CrossRef]

47. de Quintana-Schmidt, C.; Clavel-Laria, P.; Asencio-Cortes, C.; Vendrell-Brucet, J.M.; Molet-Teixido, J. Sinking skin flap syndrome. Rev. Neurol. 2011, 52, 661-664.

48. Gómez-Esteban, J.C.; Berganzo, K.; Tijero, B.; Barcena, J.; Zarranz, J.J. Orthostatic hypotension associated with an epidermoid tumor of the IV ventricle. J. Neurol. 2009, 256, 1357-1359. [CrossRef] [PubMed]

49. Ruchoux, M.M.; Gray, F.; Gherardi, R.; Schaeffer, A.; Comoy, J.; Poirier, J. Orthostatic hypotension from a cerebellar gangliocytoma (Lhermitte-Duclos disease). Case report. J. Neurosurg. 1986, 65, 245-248. [CrossRef]

50. Schatz, I.J. Orthostatic hypotension I. Functional and neurogenic causes. Arch. Intern. Med. 1984, 144, 773-777. [CrossRef]

51. Mokri, B.; Parisi, J.E.; Scheithauer, B.W.; Piepgras, D.G.; Miller, G.M. Meningeal biopsy in intracranial hypotension: Meningeal enhancement on MRI. Neurology 1995, 45, 1801-1807. [CrossRef]

52. Ulrich, N.H.; Maier, M.; Bernays, R.L.; Krayenbuhl, N.; Kollias, S. Cervical myelopathy due to chronic overshunting in a pediatric patient: Case report and review of the literature. Turk. Neurosurg. 2013, 23, 410-414. [CrossRef]

53. Howard, B.M.; Sribnick, E.A.; Dhall, S.S. Over-shunting associated myelopathy. J. Clin. Neurosci. 2014, 21, 2242-2244. [CrossRef] 
54. Liu, J.K.; Gottfried, O.N.; Brockmeyer, D.L. Epidural venous engorgement resulting in progressive cervical myelopathy from shunt-related intracranial hypotension. Case report and review of the literature. J. Neurosurg. 2006, 105, 499-503. [CrossRef]

55. Martínez-Lage, J.F.; Ruíz-Espejo, A.M.; Almagro, M.J.; Alfaro, R.; Felipe-Murcia, M.; López-Guerrero, A.L. CSF overdrainage in shunted intracranial arachnoid cysts: A series and review. Childs Nerv. Syst. 2009, 25, 1061-1069. [CrossRef] [PubMed]

56. Adib, S.D.; Hauser, T.K.; Engel, D.C.; Tatagiba, M.; Skardelly, M.; Ramina, K. Overshunting-Associated Myelopathy (OSAM) in a Patient with Bilateral Jugular Vein Occlusion. World Neurosurg. 2018, 116, 274-278. [CrossRef] [PubMed]

57. Antes, S.; Eymann, R.; Schmitt, M.; Kiefer, M. Pathophysiology of brainstem lesions due to overdrainage. Acta Neurochir. Suppl. 2012, 113, 177-180. [CrossRef] [PubMed]

58. Mencser, Z.; Kopnickzky, Z.; Kis, D.; Barzo, P. Slit Ventricle as a Neurosurgical Emergency: Case Report and Review of the Literature. World Neurosurg. 2019, 130, 493-498. [CrossRef] [PubMed]

59. Da Silva, P.S.; Suriano, I.C.; Neto, H.M. Slit like ventricle syndrome: A life-threatening presentation. Pediatr. Emerg. Care 2009, 25, 674-676. [CrossRef]

60. Martinez-Lage, J.F.; Pérez-Espejo, M.A.; Almagro, M.J.; Ros de San Pedro, J.; López, F.; Piqueras, C.; Tortosa, J. Síndromes de hiperdrenaje de las válvulas en hidrocefalia infantil. Neurocirugía 2005, 16, 124-133. [CrossRef]

61. Barami, K.; Sood, S.; Ham, S.D.; Canady, A.I. Postural Changes in Intracranial Pressure in Chronically Shunted Patients. Pediatr. Neurosurg. 2000, 33, 64-69. [CrossRef]

62. Moayeri, N.N.; Henson, J.W.; Schaefer, P.W.; Zervas, N.T. Spinal dural enhancement on magnetic resonance imaging associated with spontaneous intracranial hypotension. Report of three cases and review of the literature. J. Neurosurg. 1998, 88, 912-918. [CrossRef]

63. Matsumoto, K.; Ohta, M.; Takeshita, I. Symptomatic spinal extramedullary mass lesion secondary to chronic overdrainage of ventricular fluid-case report. Neurol. Med. Chir. 2002, 42, 140-142. [CrossRef]

64. Tuli, S.; O'Hayon, B.; Drake, J.; Clarke, M.; Kestle, J. Change in ventricular size and effect of ventricular catheter placement in pediatric patients with shunted hydrocephalus. Neurosurgery 1999, 45, 1329-1333. [CrossRef]

65. Sandler, A.L.; Goodrich, J.T.; Wagshul, M.E.; Abbott, R. A Comment on the Article by Hart et al. Entitled 'Combined Intracranial Pressure Monitoring and Cerebrospinal Fluid Infusion Study to Guide Management of Slit Ventricle Syndrome'. Pediatr. Neurosurg. 2013, 49, 258-259. [CrossRef]

66. Oi, S.; Matsumoto, S. Slit ventricles as a cause of isolated ventricles after shunting. Childs Nerv. Syst. 1985, 1, 189-193. [CrossRef]

67. Hoffman, H.J.; Tucker, W.S. Cephalocranial disproportion. A complication of the treatment of hydrocephalus in children. Childs Brain 1976, 2, 167-176. [PubMed]

68. Albright, A.; Tyler-Kabara, E. Slit-ventricle syndrome secondary to shunt-induced suture ossification. Neurosurgery 2001, 48, 764-769. [CrossRef]

69. Payner, T.D.; Prenger, E.; Berger, T.S.; Crone, K.R. Acquired Chiari malformations: Incidence, diagnosis, and management. Neurosurgery 1994, 34, 429-434. [CrossRef] [PubMed]

70. Di Rocco, C.; Velardi, F. Acquired Chiari type I malformation managed by supratentorial cranial enlargement. Childs Nerv. Syst. 2003, 19, 800-807. [CrossRef] [PubMed]

71. Kobayashi, A.; Hashi, K. Secondary spinal canal stenosis associaed with long term VP shunting. J. Neurosurg. 1983, 59, 854-860. [CrossRef] [PubMed]

72. Nomura, S.; Fujii, M.; Kajiwara, K.; Ishihara, H.; Suehiro, E.; Goto, H.; Suzuki, M. Factors influencing spinal canal stenosis in patients with long-term controlled hydrocephalus treated with cerebrospinal fluid shunt. Childs Nerv. Syst. 2010, 26, 931-935. [CrossRef]

73. Sæhle, T.; Eide, P.K. Intracranial pressure monitoring in pediatric and adult patients with hydrocephalus and tentative shunt failure: A single-center experience over 10 years in 146 patients. J. Neurosurg. 2015, 122, 1076-1086. [CrossRef]

74. Horcajadas, A.; Román, A.; Olivares, G.; Saura, E.; Jorques, A.; Cordero, N.; Ibáñez, B.; Sánchez, C.; Roldán, M.A. Utilidad de la monitorizacion de la PIC en pacientes con sospecha de disfunción valvular. Neurocirugía 2011, 22, 310-323.

75. Sood, S.; Kumar, C.R.; Jamous, M.; Schuhmann, M.U.; Ham, S.D.; Canady, A.I. Pathophysiological changes in cerebrovascular distensibility in patients undergoing chronic shunt therapy. J. Neurosurg. 2004, 100 (Suppl. S5), 447-453. [CrossRef]

76. Eide, P.K.; Sroka, M.; Wozniak, A.; Saehle, T. Morphological characterization of cardiac induced intracranial pressure (ICP) waves in patients with overdrainage of cerebrospinal fluid and negative ICP. Med. Eng. Phys. 2012, 34, 1066-1070. [CrossRef]

77. Czosnyka, M.; Czosnyka, Z.H. Overdrainage of cerebrospinal fluid and hydrocephalus shunts. Acta Neurochir. 2017, 159, 1387-1388. [CrossRef] [PubMed]

78. Oi, S.; Shimoda, M.; Shibata, M.; Honda, Y.; Togo, K.; Shinoda, M.; Tsugane, R.; Sato, O. Pathophysiology of long-standing overt ventriculomegaly in adults. J. Neurosurg. 2000, 92, 933-940. [CrossRef] [PubMed]

79. Gomes-Pinto, F.C.; Pereira, R.M.; Saad, F.; Teixeira, M.J. Performance of fixed-pressure valve with antisiphon device SPHERA ${ }^{\circledR}$ in hydrocephalus treatment and overdrainage prevention. Arq. Neuro-Psiquiatr. 2012, 70, 704-709. [CrossRef]

80. Zachenhofer, I.; Donat, M.; Roessler, K. The combination of a programmable valve and a subclavicular antigravity device in hydrocephalus patients at high risk for hygromas. Neurol. Res. 2012, 34, 219-222. [CrossRef]

81. Sood, S.; Barrett, R.J.; Powell, T.; Ham, S.D. The role of lumbar shunts in the management of slit ventricles: Does the slit-ventricle syndrome exist? J. Neurosurg. 2005, 103 (Suppl. S2), 119-123. [CrossRef] 
82. Atalay, B.; Yilmaz, C.; Cekinmez, M.; Altinors, N.; Caner, H. Treatment of hydrocephalus with functionally isolated ventricles. Acta Neurochir. 2006, 148, 1293-1296. [CrossRef] [PubMed]

83. Fattal-Valevski, A.; Beni-Adani, L.; Constantini, S. Short-term dexamethasone treatment for symptomatic slit ventricle syndrome. Childs Nerv. Syst. 2005, 21, 981-984. [CrossRef]

84. Chernov, M.F.; Kamikawa, S.; Yamane, F.; Ishihara, S.; Hori, T. Neurofiberscope-guided management of slit-ventricle syndrome due to shunt placement. J. Neurosurg. 2005, 102 (Suppl. S3), 260-267. [CrossRef]

85. Kan, P.; Walker, M.L.; Drake, J.M.; Kestle, J.R. Predicting slitlike ventricles in children on the basis of baseline characteristics at the time of shunt insertion. J. Neurosurg. 2007, 106 (Suppl. S5), 347-349. [CrossRef] [PubMed]

86. Di Rocco, C.; Iannelli, A. Complications of CSF shunting. In The Treatment of Infantile Hydrocephalus; Di Rocco, C., Ed.; CRC: Boca Raton, FL, USA, 1987; Volume II, pp. 79-153.

87. Chumas, P.D.; Armstrong, D.C.; Drake, J.M.; Kulkarni, A.V.; Hoffman, H.J.; Humphreys, R.P.; Rutka, J.T.; Hendrick, E.B. Tonsillar herniation: The rule rather than the exception after lumboperitoneal shunting in the pediatric population. J. Neurosurg. 1993, 78, 568-573. [CrossRef]

88. Lazareff, J.A.; Kelly, J.; Saito, M. Herniation of cerebellar tonsils following supratentorial shunt placement. Childs Nerv. Syst. 1998, 14, 394-397. [CrossRef]

89. Rekate, H.L.; Wallace, D. Lumboperitoneal shunts in children. Pediatr. Neurosurg. 2003, 38, 41-46. [CrossRef]

90. Major, O.; Fedorcsák, I.; Sipos, L.; Hantos, P.; Kónya, E.; Dobronyi, I.; Paraicz, E. Slit-ventricle syndrome in shunt operated children. Acta Neurochir. 1994, 127, 69-72. [CrossRef]

91. Buxton, N.; Punt, J. Subtemporal decompression: The treatment of noncompliant ventricle syndrome. Neurosurgery 1999, 44, 513-518. [CrossRef]

92. Chumas, P.D.; Drake, J.M.; Del Bigio, M.R. Death from chronic tonsillar herniation in a patient with lumboperitoneal shunt and Crouzon's disease. Br. J. Neurosurg. 1992, 6, 595-599. [CrossRef]

93. Rekate, H.L. Brain turgor (kb): Intrinsic property of the brain to resist distortion. Pediatr. Neurosurg. 1992, 18, 257-262. [CrossRef]

94. Park, S.W.; Yoon, S.H.; Cho, K.H.; Shin, Y.S. Valve pressure upgrade may produce progressive deterioration of vision in children with slit ventricle syndrome. Pediatr. Neurosurg. 2007, 43, 428-432. [CrossRef]

95. Bateman, G.A. Hypertensive slit ventricle syndrome: Pseudotumor cerebri with a malfunctioning shunt? J. Neurosurg. 2013, 119, 1503-1510. [CrossRef]

96. Preuss, M.; Hoffmann, K.T.; Reiss-Zimmermann, M.; Hirsch, W.; Merkenschlager, A.; Meixensberger, J.; Dengl, M. Updated physiology and pathophysiology of CSF circulation-the pulsatile vector theory. Childs Nerv. Syst. 2013, 29, 1811-1825. [CrossRef]

97. Barami, K.; Sood, S. The cerebral venous system and the postural regulation of intracranial pressure: Implications in the management of patients with cerebrospinal fluid diversion. Childs Nerv. Syst. 2016, 32, 599-607. [CrossRef]

98. Liniger, P.; Marchand, S.; Kaiser, G.L. Flow control versus antisiphon valves: Late results concerning slit ventricles and slitventricle syndrome. Eur. J. Pediatr. Surg. 2003, 13 (Suppl. S1), S3-S6. [CrossRef] [PubMed]

99. Alavi, S.; Schulz, M.; Schaumann, A.; Schwarz, K.; Thomale, U.W. Valve exchange towards an adjustable differential pressure valve with gravitational unit, clinical outcome of a single-center study. Childs Nerv. Syst. 2017, 33, 759-765. [CrossRef] [PubMed]

100. Thomale, U.W.; Gebert, A.F.; Haberl, H.; Schulz, M. Shunt survival rates by using the adjustable differential pressure valve combined with a gravitational unit (proGAV) in pediatric neurosurgery. Childs Nerv. Syst. 2013, 29, 425-431. [CrossRef]

101. Rohde, V.; Mayfrank, L.; Ramakers, V.T.; Gilsbach, J.M. Four year experience with the routine use of the programmable Hakim valve in the management of children with hydrocephalus. Acta Neurochir. 1998, 140, 1127-1134. [CrossRef] [PubMed]

102. Aschoff, A.; Kremer, P.; Hashemi, B.; Kunze, S. The scientific history of hydrocephalus and its treatment. Neurosurg. Rev. 1999, 22, 67-93. [CrossRef]

103. Gruber, R.W.; Roehrig, B. Prevention of ventricular catheter obstruction and slit ventricle syndrome by the prophylactic use of the Integra antisiphon device in shunt therapy for pediatric hypertensive hydrocephalus: A 25-year follow-up study. J. Neurosurg. Pediatr. 2010, 5, 14-16. [CrossRef]

104. Sotelo, J. The hydrokinetic parameters of shunts for hydrocephalus might be inadequate. Surg. Neurol. Int. 2012, 3, 40. [CrossRef] [PubMed]

105. Gehlen, M.; Eklund, A.; Kurtcuoglu, V.; Malm, J.; Daners, M.S. Comparison of anti-siphon devices—how do they affect CSF dynamics in supine and upright posture? Acta Neurochir. 2017, 159, 1389-1397. [CrossRef]

106. Gomes Pinto, F.C.; Fernandes de Oliveira, M.; Souza de Castro, J.P.; Rocha Morais, J.V.; Gomes Pinto, F.M.; Teixeira, M.J. Clinical performance of fixed-pressure Sphera Duo ${ }^{\circledR}$ hydrocephalus shunt. Arq. Neuro-Psiquiatr. 2020, 78, 9-12. [CrossRef]

107. Bozhkov, Y.; Roessler, K.; Hore, N.; Buchfelder, M.; Brandner, S. Neurological outcome and frequency of overdrainage in normal pressure hydrocephalus directly correlates with implanted ventriculo-peritoneal shunt valve type. Neurol. Res. 2017, 39, 601-605. [CrossRef] [PubMed]

108. Freimann, F.B.; Kimura, T.; Stockhammer, F.; Schulz, M.; Rohde, V.; Thomale, U.W. In vitro performance and principles of anti-siphoning devices. Acta Neurochir. 2014, 156, 2191-2199. [CrossRef]

109. Freimann, F.B.; Luhdo, M.L.; Rohde, V.; Vajkoczy, P.; Wolf, S.; Sprung, C. The Frankfurt horizontal plane as a reference for the implantation of gravitational units: A series of 376 adult patients. Acta Neurochir. 2014, 156, 1351-1356. [CrossRef]

110. Lemke, J.; Meier, U. Improved outcome in shunted iNPH with a combination of a Codman Hakim programmable valve and an Aeskulap-Miethke ShuntAssistant. Cent. Eur. Neurosurg. 2010, 71, 113-116. [CrossRef] 
111. Lemcke, J.; Meier, U.; Müller, C.; Fritsch, M.; Kiefer, M.; Eymann, R.; Kehler, U.; Langer, N.; Schuhmann, M.U.; Speil, A.; et al. On the method of a randomised comparison of programmable valves with and without gravitational units: The SVASONA study. Acta Neurochir. Suppl. 2012, 114, 243-246. [CrossRef] [PubMed]

112. Desai, V.R.; Sadrameli, S.S.; Jenson, A.V.; Asante, S.K.; Daniels, B.; Trask, T.W.; Britz, G. Ventriculoperitoneal shunt complications in an adult population: A comparison of various shunt designs to prevent overdrainage. Surg. Neurol. Int. 2020, 11, 269. [CrossRef] [PubMed]

113. Kaestner, S.; Kruschat, T.; Nitzsche, N.; Deinsberger, W. Gravitational shunt units may cause under-drainage in bedridden patients. Acta Neurochir. 2009, 151, 217-221. [CrossRef]

114. Alvarado, A.; Boyle, J.; Martinez, D.; Avellino, A.M.; Lin, J. Commentary to Postural Headache Associated with VentriculoPeritoneal Shunt Overdrainage: What are Our Options. Neurosurgery 2017, 80, E247-E248. [CrossRef]

115. Freimann, F.P.; Schulz, M.; Haberl, H.; Thomale, U.W. Feasibility of telemetric ICP-guided valve adjustments for complex shunt therapy. Childs Nerv. Syst. 2014, 30, 689-697. [CrossRef]

116. Diesner, N.; Freimann, F.; Clajus, C.; Kallenberg, K.; Rohde, V.; Stockhammer, F. Female gender predisposes for cerebrospinal fluid overdrainage in ventriculoperitoneal shunting. Acta Neurochir. 2016, 158, 1273-1278. [CrossRef]

117. Antes, S.; Stadie, A.; Müller, S.; Linsler, S.; Breuskin, D.; Oertel, J. Intracranial Pressure Guided Shunt Valve Adjustments with the Miethke Sensor Reservoir. World Neurosurg. 2018, 109, e642-e650. [CrossRef]

118. Tschan, C.A.; Antes, S.; Huthmann, A.; Vulcu, S.; Oertel, J.; Wagner, W. Overcoming CSF overdrainage with the adjustable gravitational valve proSA. Acta Neurochir. 2014, 156, 767-776. [CrossRef]

119. Suchorska, B.; Kunz, M.; Schniepp, R.; Jahn, K.; Goetz, C.; Tonn, J.C.; Peraud, A. Optimized surgical treatment for normal pressure hydrocephalus: Comparison between gravitational and differential pressure valve. Acta Neurochir. 2015, 157, 703-709. [CrossRef]

120. Meier, U.; Kiefer, M.; Neumann, U.; Lemcke, J. On the optimal opening pressure of hydrostatic valves in cases of idiopathic normal-pressure hydrocephalus: A prospective randomized study with 123 patients. Acta Neurochir. Suppl. 2006, 96, 358-363. [CrossRef]

121. Freimann, F.B.; Vajkoczy, P.; Sprung, C. Patients benefit from low-pressure settings enabled by gravitational valves in normal pressure hydrocephalus. Clin. Neurol. Neurosurg. 2013, 115, 1982-1986. [CrossRef]

122. Trinh, V.T.; Duckworth, E.A. Revision to an adjustable nonsiphon control valve in low pressure hydrocephalus: Therapeutic siphoning and a new perspective on NPH: Series of 3 cases and review of the literature. Clin. Neurol. Neurosurg. 2013, 115, 175-178. [CrossRef] [PubMed]

123. Funnell, J.P.; D’Antona, L.; Craven, C.L.; Thorne, L.; Watkins, L.D.; Toma, A.K. Ultra-low-pressure hydrocephalic state in NPH: Benefits of therapeutic siphoning with adjustable antigravity valves. Acta Neurochir. 2020, 162, 2967-2974. [CrossRef] [PubMed]

124. Gutowski, P.; Rot, S.; Fritsch, M.; Meier, U.; Gölz, L.; Lemcke, J. Secondary deterioration in patients with normal pressure hydrocephalus after ventriculoperitoneal shunt placement: A proposed algorithm of treatment. Fluids Barriers CNS 2020, 17, 18. [CrossRef] [PubMed]

125. Steinbok, P.; Poskitt, K.J.; Cochrane, D.D.; Kestle, J.R. Prevention of postshunting ventricular asymmetry by transseptal placement of ventricular catheters. A randomized study. Pediatr. Neurosurg. 1994, 21, 59-64. [CrossRef] [PubMed]

126. Gil, Z.; Siomin, V.; Beni-Adani, L.; Sira, B.; Constantini, S. Ventricular catheter placement in children with hydrocephalus and small ventricles: The use of a frameless neuronavigation system. Childs Nerv. Syst. 2002, 18, 26-29. [CrossRef]

127. Oi, S.; Abott, R. Loculated ventricles and isolated compartments in hydrocephalus: Their pathophysiology and the efficacy of neuroendoscopic surgery. Neurosurg. Clin. N. Am. 2004, 15, 77-87. [CrossRef]

128. Harter, D.H. Management strategies for treatment of the trapped fourth ventricle. Childs Nerv. Syst. 2004, 20, 710-716. [CrossRef]

129. Udayakumaran, S.; Biyani, N.; Rosenbaum, D.P.; Ben-Sira, L.; Constantini, S.; Beni-Adani, L. Posterior fossa craniotomy for trapped fourth ventricle in shunt-treated hydrocephalic children: Long-term outcome. J. Neurosurg. Pediatr. 2011, 7, 52-63. [CrossRef]

130. Butler, W.E.; Khan, S.A. The application of controlled intracranial hypertension in slit ventricle syndrome patients with obstructive hydrocephalus and shunt malfunction. Pediatr. Neurosurg. 2001, 35, 305-310. [CrossRef]

131. Iglesias, S.; Ros, B.; Ibáñez, G.; Delgado, A.; Ros, A.; Arráez, M.A. Shunt independence in paediatric hydrocephalus: Our 16-year experience and review. Childs Nerv. Syst. 2019, 35, 1547-1555. [CrossRef]

132. Nadkarni, T.D.; Rekate, H.L.; Wallace, D. Concurrent use of a lumboperitoneal shunt with programable valve and ventricular acceess device in the treatment of pseudotumor cerebri: Review of 40 cases. J. Neurosurg. Pediatr. 2008, 2, 19-24. [CrossRef]

133. Wang, V.Y.; Barbaro, N.M.; Lawton, M.T.; Pitts, L.; Kunwar, S.; Parsa, A.T.; Gupta, N.; McDermott, M.W. Complications of lumboperitoneal shunts. Neurosurgery 2007, 60, 1045-1048; discussion 1049. [CrossRef]

134. Yadav, Y.R.; Parihar, V.; Sinha, M. Lumbar peritoneal shunt. Neurol. India 2010, 58, 179-184. [CrossRef]

135. Yang, T.H.; Chang, C.S.; Sung, W.W.; Liu, J.T. Lumboperitoneal Shunt: A New Modified Surgical Technique and a Comparison of the Complications with Ventriculoperitoneal Shunt in a Single Center. Medicina 2019, 55, 643. [CrossRef]

136. Rekate, H.L.; Nadkarni, T.; Wallace, D. Severe intracranial hypertension in slit ventricle syndrome managed using a cisterna magna-ventricle-peritoneum shunt. J. Neurosurg. 2006, 104 (Suppl. S4), 240244. [CrossRef]

137. Obana, W.G.; Raskin, N.H.; Cogen, P.H.; Szymanski, J.A.; Edwards, M.S. Antimigraine treatment for slit ventricle syndrome. Neurosurgery 1990, 27, 760-763. [CrossRef] 
138. Walsh, J.W.; James, H.E. Subtemporal craniectomy and elevation of shunt valve opening pressure in the management of small ventricle-induced cerebrospinal fluid shunt dysfunction. Neurosurgery 1982, 10 Pt 1, 698-703. [CrossRef]

139. Gough, J.; Walker, D.G.; Theile, R.; Tomlinson, F.H. The role of cranial expansion for craniocephalic disproportion. Pediatr. Neurosurg. 2005, 41, 61-69. [CrossRef]

140. Martínez-Lage, J.F.; Ruiz-Espejo Vilar, A.; Pérez-Espejo, M.A.; Almagro, M.J.; Ros de San Pedro, J.; Felipe Murcia, M. Shunt-related craniocerebral disproportion: Treatment with cranial vault expanding procedures. Neurosurg. Rev. 2006, 29, 229-235. [CrossRef] [PubMed]

141. Weinzweig, J.; Bartlett, S.P.; Chen, J.C.; Losee, J.; Sutton, L.; Duhaime, A.C.; Whitaker, L.A. Cranial Vault Expansion in the Management of Postshunt Craniosynostosis and Slit Ventricle Syndrome. Plast. Reconstr. Surg. 2008, 122, 1171-1180. [CrossRef]

142. Hankinson, T.C.; Mocco, J.; Kimball, B.; Anderson, R.C.; Feldstein, N.A. Internal cranial expansion procedure for the treatment of symptomatic intracranial hypertension. J. Neurosurg. 2007, 107 (Suppl. S5), 402-405. [CrossRef]

143. Ellis, J.A.; Anderson, R.C.; O'Hanlon, J.; Goodman, R.R.; Feldstein, N.A.; Ghatan, S. Internal cranial expansion surgery for the treatment of refractory idiopathic intracranial hypertension. J. Neurosurg. Pediatr. 2012, 10, 14-20. [CrossRef]

144. Fabiano, A.J.; Siddiqui, A.H. Spinal cord syrinx expansion following acquired Chiari malformation decompression: Case report. Clin. Neurol. Neurosurg. 2010, 112, 832-834. [CrossRef] [PubMed]

145. Peleggi, A.F.; Lovely, T.J. Treatment of delayed Chiari malformation and syringomyelia after lumboperitoneal shunt placement: Case report and treatment recommendations. Surg. Neurol. Int. 2012, 3, 101. [CrossRef] [PubMed] 